\title{
The Deflection of the China Coastal Current over the Taiwan Bank in Winter
}

\author{
ENHUI LIAO \\ State Key Laboratory of Marine Environmental Science, Xiamen University, Xiamen, China, and College of Earth, Ocean, \\ and Environment, University of Delaware, Newark, Delaware \\ LIE YAUW OEY \\ National Taiwan University, Jhongli City, Taiwan, and Princeton University, Princeton, New Jersey
}

XIAO-HAI YAN

College of Earth, Ocean, and Environment, University of Delaware, Newark, Delaware, and State Key Laboratory of Marine Environmental Science, Xiamen University, Xiamen, China

LI LI

Third Institute of Oceanography, State Oceanic Administration, and State Key Laboratory of Marine Environmental Science, Xiamen University, Xiamen, China

\section{YUWU JIANG}

State Key Laboratory of Marine Environmental Science, Xiamen University, Xiamen, China

(Manuscript received 23 February 2017, in final form 19 April 2018)

\begin{abstract}
In winter, an offshore flow of the coastal current can be inferred from satellite and in situ data over the western Taiwan Bank. The dynamics related to this offshore flow are examined here using observations as well as analytical and numerical models. The currents can be classified into three regimes. The downwind (i.e., southward) cold coastal current remains attached to the coast when the northeasterly wind stress is stronger than a critical value depending on the upwind (i.e., northward) large-scale pressure gradient force. By contrast, an upwind warm current appears over the Taiwan Bank when the wind stress is less than the critical pressure gradient force. The downwind coastal current and upwind current converge and the coastal current deflects offshore onto the bank during a moderate wind. Analysis of the vorticity balance shows that the offshore transport is a result of negative bottom stress curl that is triggered by the positive vorticity of the two opposite flows. The negative bottom stress curl is reinforced by the gentle slope over the bank, which enhances the offshore current. Composite analyses using satellite observations show cool waters with high chlorophyll in the offshore current under moderate wind. The results of composite analyses support the model findings and may explain the high productivity over the western bank in winter.
\end{abstract}

\section{Introduction}

A coastal current is observed along the coast of China in winter. Along the China Coastal Current (CCC), wavelike meanders and offshore flows along the length of the current exist as the current flows southward from

Supplemental information related to this paper is available at the Journals Online website: https://doi.org/10.1175/JPO-D-17-0037.s1.

Corresponding author: Yuwu Jiang, ywjiang@xmu.edu.cn the East China Sea, through the Taiwan Strait, and into the South China Sea. These variabilities can be due to an alongshore change in pycnocline undulation, changes in coastline and bathymetry, and flow convergence or divergence (Gan et al. 2013; Oey et al. 2014; Wang and Oey 2016; Wu 2015). Two significant offshore flows often occur in the north around Pingtan Island and in the southern Taiwan Strait near a prominent submarine bump, the Taiwan Bank (TWB; Fig. 1). In some years of anomalously strong winter monsoon, the CCC carries unusually cold water $\left(<16^{\circ} \mathrm{C}\right)$ southward and the 


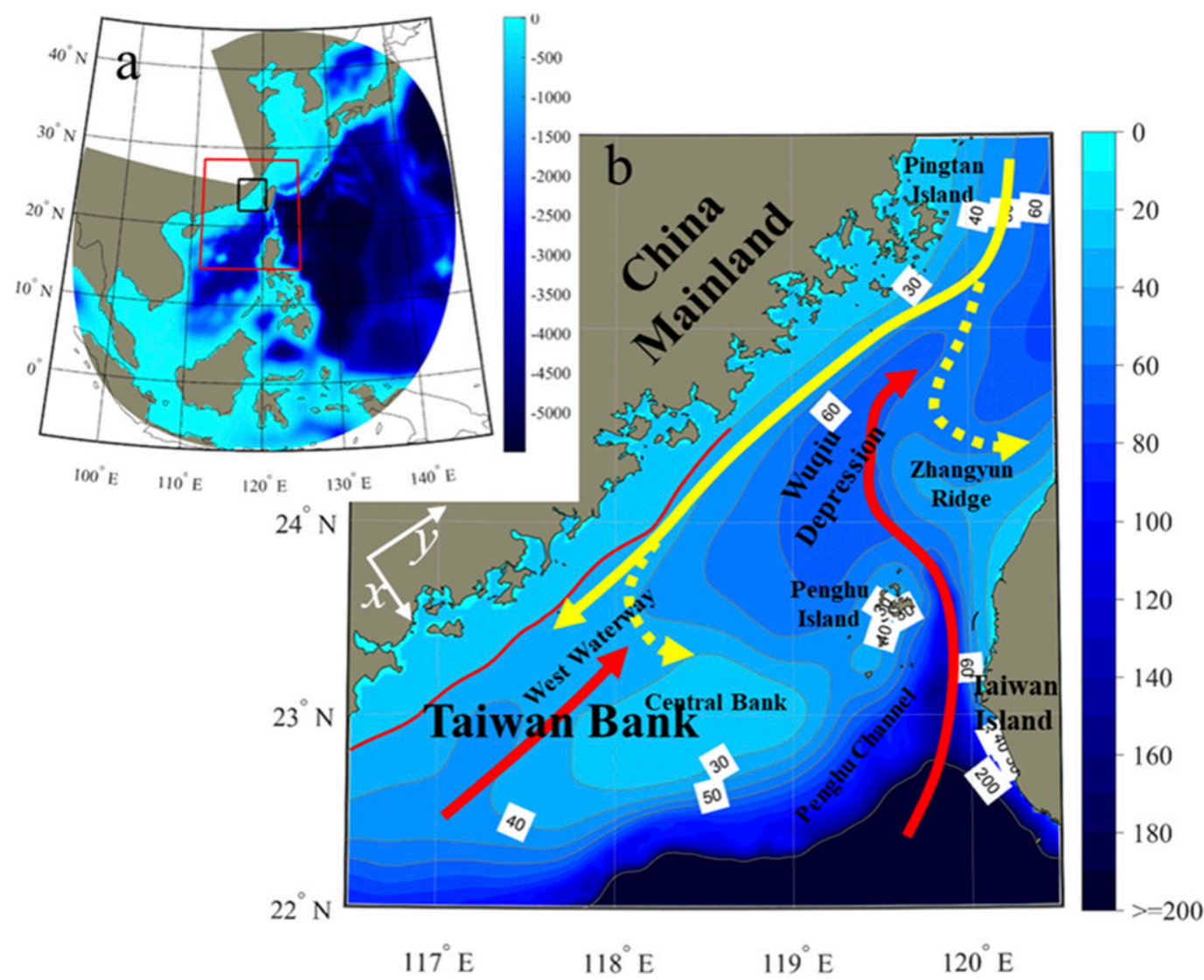

FIG. 1. (a) The model domain and (b) the topography around the Taiwan Bank. (a) The color shading region is the domain of the coarse grid, the red box is the fine grid, and the black box is the focus region that is zoomed in on in (b). (b) The Taiwan Bank as a focus region is divided into three parts: West Waterway, Central Bank (30-m isobaths in the center), and Penghu Channel. The gray lines are the isobaths. The thin red line is the 30-m isobath used for transect analysis. The yellow arrow represents the southward (downwind) coastal current, and the dashed yellow arrows are the offshore flows in the northern and southern strait. The red arrow in the West Waterway is the SCSWC's extension, and the other red arrow in the Penghu Channel represents the SCSWC's extension and Kuroshio Extension. The schematic coordinate (alongshore and cross-shore) is plotted as the white line.

offshore flow in the northern strait transports the cold coastal water offshore to Penghu Island (Hsieh et al. 2008; Liao et al. 2013a, 2015; Tang 1978). The unusually cold water can cause a devastating disruption of the local coral reef and the ecosystem. Lee et al. (2014) reported a $50 \%-80 \%$ decrease in fish catch when the cold water meander occurred in 2008. The offshore flow at the TWB also has a significant influence on the local ecosystem and is the focus of this study (Figs. 2 and 3).

The CCC water has low salinity (28-34 psu), low temperature $\left(5^{\circ}-20^{\circ} \mathrm{C}\right.$ ), and high nutrients (Hong et al. 2011; Huang 1989; Oey et al. 2013). The current is along the China coastline with a speed of $0.1-0.3 \mathrm{~m} \mathrm{~s}^{-1}$, and its width extends to as far as the 60-m isobath depending on the strength of the wind (Hu et al. 1999; Pan et al. 2013). On the shelf of the northern South China Sea, the circulation is complicated by the presence of complex coastlines and variable bathymetry, as well as the existence of counter-wind (i.e., northward) South China Sea warm current (SCSWC; Fig. 1; Hu et al. 2010). In the East China Sea, offshore-penetrating tongues of CCC water are often observed (Wu 2015). In the northern Taiwan Strait, a branch of the CCC (Fig. 1) often makes a U-turn to join the northward-flowing Taiwan warm current (Liao et al. 2013a; Oey et al. 2014).

The TWB is a significant topographic feature with an area of approximately $160 \mathrm{~km} \times 160 \mathrm{~km}$ (characterized by the $40-\mathrm{m}$ isobath). The submarine bank consists of a large area of sandy shoals including submarine sand waves with crests as shallow as $20 \mathrm{~m}$ (Shao et al. 2011). The shallowest portion of the bank is in the center with a deep submarine valley (Penghu Channel) to the east and a shallow waterway to the west. The Penghu Channel slopes steeply to a depth of $2000-3000 \mathrm{~m}$ into 

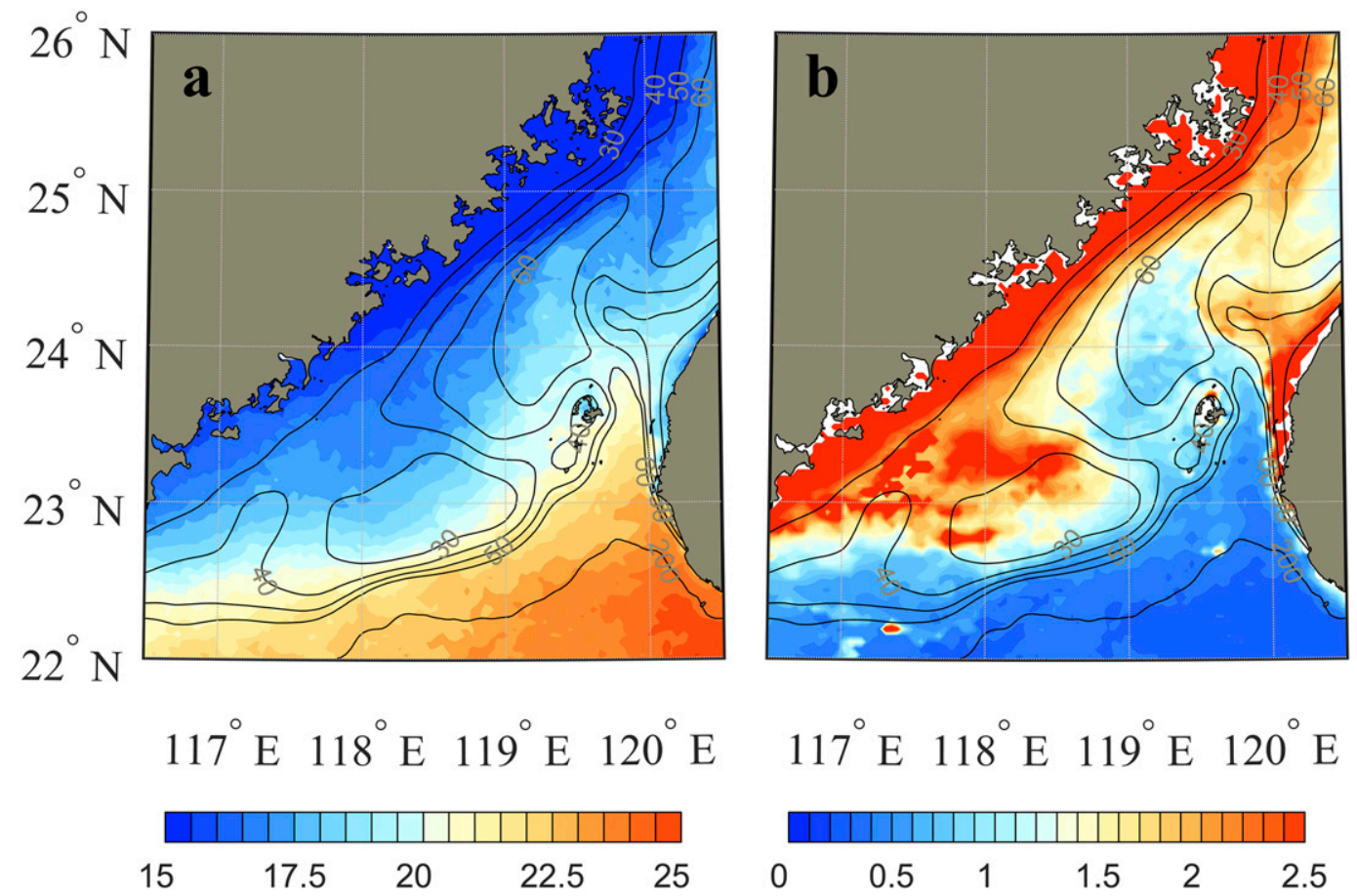

FIG. 2. (a) The SST $\left({ }^{\circ} \mathrm{C}\right)$ and (b) chlorophyll $\left(\mathrm{mg} \mathrm{m}^{-3}\right)$ composites of those times when the wind is intermediate (from $-0.67 \times 10^{-4}$ to $-1.14 \times 10^{-4} \mathrm{~m}^{2} \mathrm{~s}^{-2}$, or $7-9 \mathrm{~m} \mathrm{~s}^{-1}$ ) in winter. The SST and chlorophyll are MODIS data. The wind criterion is computed in section 4 . Winter time is defined as December, January, and February. The black lines are the isobaths from 30 to $60 \mathrm{~m}$ with a spacing of $10 \mathrm{~m}$.

the South China Sea, while the West Waterway widens to merge with the China coastline and has an averaged depth of $35 \mathrm{~m}$. In winter, circulation in the Taiwan Strait is influenced by two forces in opposite directions: northeasterly monsoon wind and open-ocean, upwind (i.e., northward) pressure gradient force associated with the Kuroshio and warmer water of the South China Sea (Oey et al. 2010; Yang 2007). Considering the different forcing influences, we divide the study region into three parts: West Waterway, Central Bank (30-m isobath in the center), and Penghu Channel (Fig. 1). A persistent northward flow dominated by the open-ocean forcing is
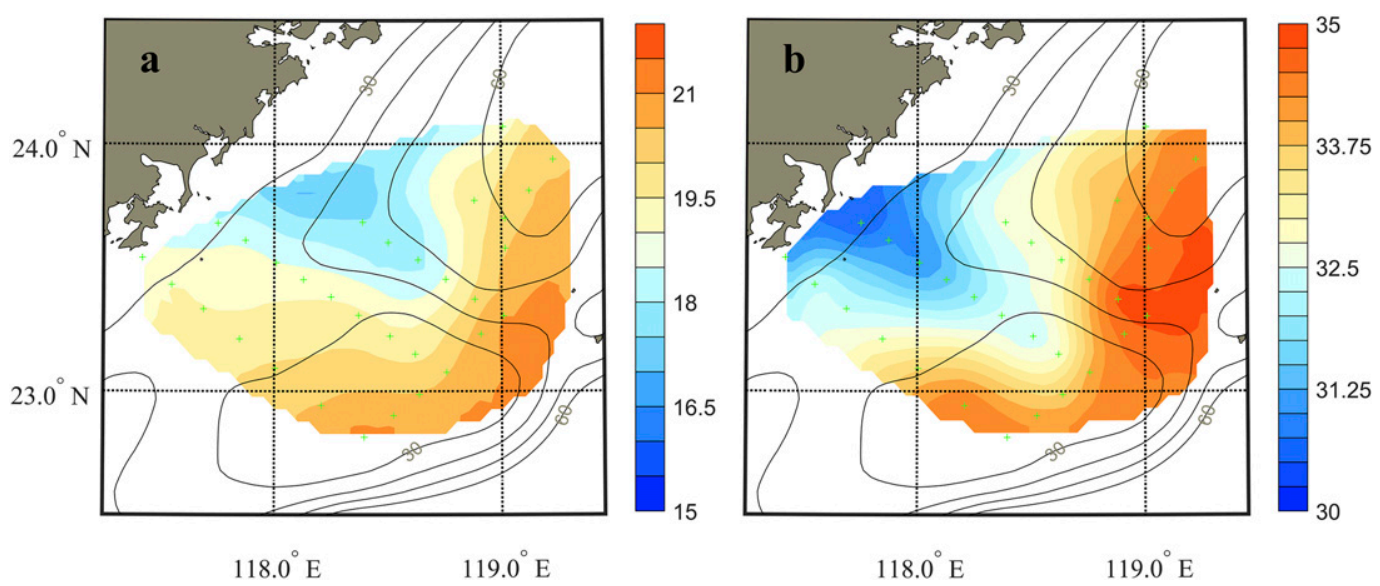

FIG. 3. (a) The observed temperature $\left({ }^{\circ} \mathrm{C}\right)$ and (b) salinity (psu) distributions (20-m depth) around the Taiwan Bank. The observation is conducted by the China Third Institute of Oceanography over the period 2 Dec $2007-$ $8 \mathrm{Jan} 2008$. The green plus symbols are survey sites. The black lines are the isobaths from 30 to $60 \mathrm{~m}$ with a spacing of $10 \mathrm{~m}$. 
observed in the deep Penghu Channel (Jan and Chao 2003; Lin et al. 2005). The West Waterway is alternatively occupied by the southward coastal current and the northward SCSWC depending on the balance between wind and open-ocean forcing (Guan and Fang 2006; Zhu et al. 2013). Some studies stated that the CCC ends in the TWB, blocked by the TWB and the northward SCSWC (Wu 1982; Xiao et al. 2002), while others indicated that the coastal current can reach as far south as Hainan Island in the South China Sea in some years of strong winter monsoon (Guan and Fang 2006).

Flow variations in the vicinity of submarine banks have been reported in the literature. Whitney and Allen (2009) indicated a downwelling jet is weakened over the Heceta Bank. Gong et al. (2015) reported an increased cross-shelf transport associated with a coastal sea level setup during the strong winter storm period. Gula et al. (2015) suggested that local along-isobath pressure anomalies and topographic form stresses exerted by the Charleston Bump retard the Gulf Stream and steer the current seaward. Gan et al. (2013) pointed out that the bottom stress curl can induce an alongshore pressure gradient that then intensifies a geostrophic downslope cross-shore current over a widened shelf in the northern part of the South China Sea. The cross-shore transport in the northern Taiwan Strait is associated with the nonlinear term in the vorticity equation that is contributed by a stationary topographic Rossby wave over the lee of the Zhangyu Ridge (Oey et al. 2014).

To understand the circulation and underlying dynamics of the offshore transport in the TWB, a numerical model and theoretical analysis are used in this study. This paper is organized as follows. The spatial features of the offshore flow are identified first in observational data. After a description and validation of the numerical model, the criterion for the occurrence of offshore flow is derived using model results. The mechanism is then investigated through vorticity equation and numerical experiments. The conclusions are summarized in the last section.

\section{Observations}

There are some studies (Li et al. 2006; Guan and Fang 2006) on the SST front over the TWB; however, the deflection of cold water has not been reported. In this section, we examine the general features of the cold water deflection using satellite data and ship data. The satellite data consist of SST, chlorophyll, and wind. The SST and chlorophyll are from NASA Moderate Resolution Imaging Spectroradiometer (MODIS) Terra. The MODIS/Terra acquires data in 36 spectral bands covering the globe in two days. In this study, we use mapped 4-km- and 8-day-resolution SST from 2002 to 2015 (https://oceandata.sci.gsfc.nasa.gov). The wind is from cross-calibrated multiplatform (CCMP) version 2 gridded surface vector wind products. The CCMP data are produced using version-7 Remote Sensing Systems (RSS) radiometer wind speeds, QuikSCAT and ASCAT scatterometer wind vectors, moored buoy wind data, and ERA-Interim model wind fields. The variational analysis method (VAM) is applied to produce four maps daily of $0.25^{\circ}$ gridded vector winds (http://www.remss. com/measurements/ccmp). We also use data from a vessel survey by the China Third Institute of Oceanography over 2 December 2007-8 January 2008 (Pan et al. 2013; Qiu et al. 2012).

The separated cold water brings nutrients into the TWB, leading to phytoplankton growth. Therefore, we choose both chlorophyll and SST as indicators of cold water deflection. The coastal current tends to deflect under an "intermediate" wind stress $\left(-1.14 \times 10^{-4}<\tau<-0.67 \times\right.$ $10^{-4} \mathrm{~m}^{2} \mathrm{~s}^{-2}$ ) that will be theoretically determined below. Figure 2 shows the SST and chlorophyll composites of those times when the wind is intermediate.

An offshore movement of cold water can be identified in Fig. 2a. The cold $\left(10^{\circ}-16^{\circ} \mathrm{C}\right)$ water is along the coast, which is considered the CCC, and the warm $\left(>20^{\circ} \mathrm{C}\right)$ water dominates the open ocean, which is regarded as the SCSWC and Kuroshio Extension. The cold water $\left(16^{\circ} \mathrm{C}\right)$ leaves the coast at $23.5^{\circ} \mathrm{N}$, crosses the West Waterway, and extends to the Central Bank. Correspondingly, the chlorophyll anomaly shows a high concentration in the West Waterway (Fig. 2b) when the cold water spreads to the open ocean. Wang et al. (2016) showed the offshore flow in the northern strait can trigger a winter bloom during the wind relaxation, when the CCC water with high nutrient and low density transports offshore, enhancing the stratification. Further study is needed for the detailed mechanism of high chlorophyll concentration in the southern strait. The separated pattern is much more distinct in the chlorophyll than SST, which may be due to the strong winter wind and surface heat fluxes that can rapidly modify the SST. This relationship between cold water and high chlorophyll suggests that the physical process of deflection is important to the regional marine ecosystem and fishery, further justifying a study of the phenomenon.

A clear example of coastal current deflection over the TWB can be seen in observed salinity and temperature (20-m depth) in January 2008 (Fig. 3). Offshore spreading of cold and fresh water is observed over the TWB. The cold and fresh water considered as the coastal current deflects from the 30-m isobath near the coast at $23.5^{\circ} \mathrm{N}$ and crosses the West Waterway (Figs. 3a,b). Here, too, the feature is more distinct in salinity than in 

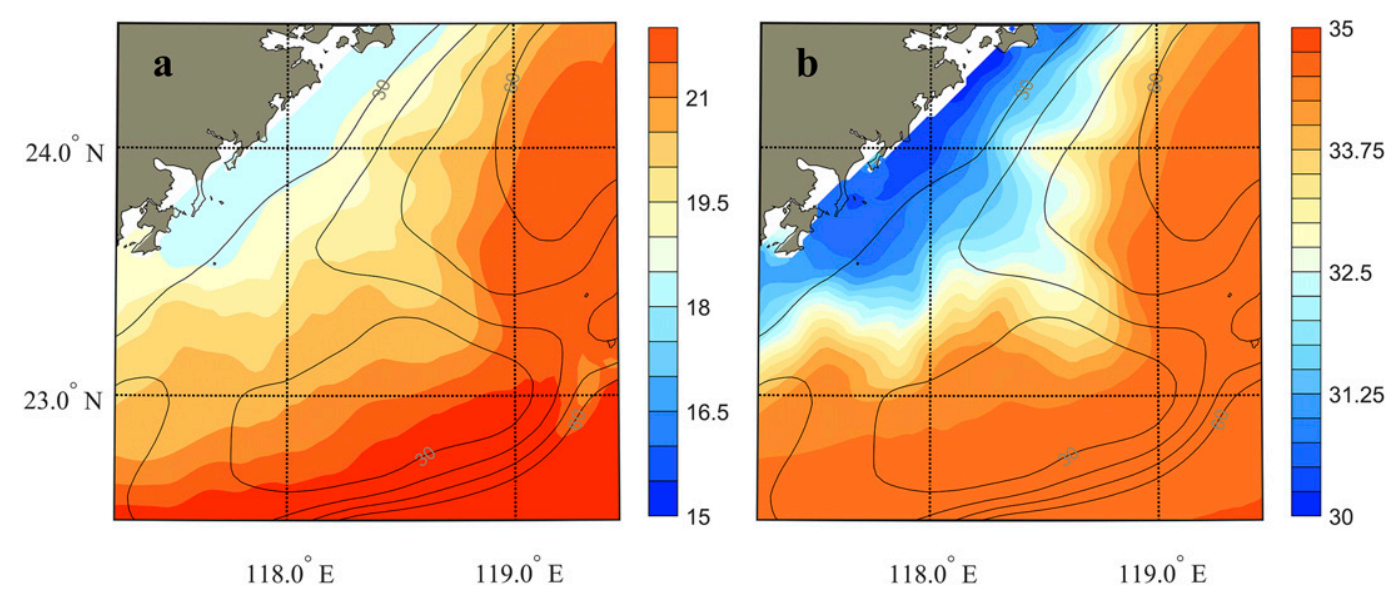

FIG. 4. (a) The simulated temperature $\left({ }^{\circ} \mathrm{C}\right)$ and (b) salinity (psu) distributions (20-m depth) around the Taiwan Bank. The model results are on 22 Dec 2007. The black lines are the isobaths from 30 to $60 \mathrm{~m}$ with a spacing of $10 \mathrm{~m}$.

SST, as the former is less affected by the strong surface heat flux. A clear front can be seen over the TWB with cold $\left(17^{\circ}-19^{\circ} \mathrm{C}\right)$ and fresh $(31-33$ psu) water near the coast and warm $\left(>20^{\circ} \mathrm{C}\right)$ and salty $(>34 \mathrm{psu})$ water in the open ocean (Fig. 3). Both satellite and in situ observations thus show a clear coastal current deflection pattern at $23.5^{\circ} \mathrm{N}$.

\section{Model configuration}

The numerical model used in this study is a one-way nested model based on the Regional Ocean Modeling System (ROMS; Shchepetkin and McWilliams 2003, 2005). The coarse grid is from the Taiwan Strait Nowcast/ Forecast System (TFOR), which has served as an operational forecasting system for the Fujian Province Marine Forecasting Institute since 2003 (Lin et al. 2016). The TFOR has been extensively tested and validated, and the results have been used to study various oceanic phenomena in the Taiwan Strait (Chen et al. 2014; Liao et al. 2017, 2013a,b; Lu et al. 2015; Wang et al. 2013). The model covers the northwestern Pacific from $8.5^{\circ} \mathrm{S}$ to $45.0^{\circ} \mathrm{N}$ and $93.0^{\circ}$ to $148^{\circ} \mathrm{E}$ (Fig. 1) with a curvilinear grid at a horizontal resolution of 1.5 to $45 \mathrm{~km}$ and with 30 vertical terrain-following levels. The nested fine grid focuses on the Taiwan Strait from $14.5^{\circ}$ to $28.4^{\circ} \mathrm{N}$ and $111.4^{\circ}$ to $125.2^{\circ} \mathrm{E}$ (Fig. 1 ) at a $1 / 32^{\circ} \times 1 / 32^{\circ}$ horizontal resolution and 25 vertical terrain-following levels. The model bathymetry consists of survey data and ETOPO2v2 from the National Geophysical Data Center. To reduce the sigma-coordinate pressure gradient truncation errors, a depth filter by Mellor et al. (1998) is applied to smooth the bathymetry. The surface forcing data, consisting of wind stress, net heat flux, and fresh water flux, are from MERCATOR PSY3V2R2 (https://www.mercator-ocean.fr/en/). The surface net heat flux is obtained by the prescribed climatological surface net heat flux and a correction term proportional to the difference between the climatological SST and the model SST (Barnier et al. 1995). The initial and lateral boundary conditions of the fine-grid model are interpolated from the coarse-grid model. In addition, the lateral boundary condition includes major rivers' discharge along the China coast and sea level forcing by 10 main tidal components (i.e., $\mathrm{M}_{2}, \mathrm{~S}_{2}, \mathrm{~N}_{2}, \mathrm{~K}_{2}, \mathrm{~K}_{1}, \mathrm{O}_{1}, \mathrm{P}_{1}$, $\mathrm{Q}_{1}, \mathrm{M}_{\mathrm{f}}$, and $\mathrm{M}_{\mathrm{m}}$ ) from TPXO7.0 (Egbert and Erofeeva 2002).

The default ROMS schemes for horizontal and vertical advection terms of momentum and tracer equation are used: the third-order upstream bias and fourth order centered for horizontal and vertical advections of 3D momentum, respectively, and fourth order centered for 2D momentum and tracer equations. The Smagorinsky diffusion is used for the harmonic horizontal mixing of tracers, which occurs along the geopotential surface. The vertical viscosity and diffusivity are calculated by the Mellor and Yamada (1982) (MY2.5) turbulence model. The radiation boundary condition employs the Flather (Flather 1987) scheme for the 2D momentum. The Chapman boundary condition is chosen for the model to include background elevation and tidal processes (Chapman 1985), and the clamped boundary condition is employed for the 3D momentum and tracers (temperature and salinity).

The model results from October 2007 to February 2008 were selected to compare with the in situ data in 2008 and theoretical analysis. The simulated temperature and salinity distributions are plotted in Figs. 4a and $4 \mathrm{~b}$, respectively. The simulations demonstrate an offshore extension of the coastal current in the West 
Waterway that is similar to in situ data during the winter of 2008 (Fig. 3). The cold and fresh coastal current appears to be blocked by the submarine bump and warm and salty water from the south and could not flow pass the TWB as a branch of it extends from the 30-m isobath to the Central Bank at $23.5^{\circ} \mathrm{N}$. A north-southward temperature gradient over the TWB can be seen. The model simulates well the offshore flow and will be used to analyze the underlying dynamics. The model was extensively validated against time series of velocity and temperature (January and February in 2008) in Liao et al. (2013a), in which we studied an unusually cold event in February 2008 in the northern Taiwan Strait. The velocity validation in Liao et al. (2013a) shows that the correlation coefficient of the cross-shore and alongshore velocities between observations and model outputs are 0.61 and 0.74 , respectively.

\section{Classification of circulation regimes}

Before analyzing the mechanism of the offshore flow, we present in this section a simple model to estimate the wind criteria for the offshore flow. Since the wind condition in this region is northeasterly monsoon, which almost parallels the coastline, the wind criteria refers to the alongshore wind range. When the offshore flow emerges over the TWB, an alongshore downwind flow along the coastline and upwind flow (countercurrent) on the shelf are observed to the north and south of the TWB, respectively. The simultaneous occurrence of these three flows (i.e., offshore, downwind, and upwind flows) indicates the wind criteria for the offshore flow can also be adopted to diagnose the two alongshore flows opposite to each other (i.e., the alongshore downwind and upwind flows to the north and south of TWB).

To simplify the dynamics, three regions were selected to diagnose the momentum balance. These three regions are Rntwb (Region North Taiwan Bank), Rstwb (Region South Taiwan Bank), and Rtwb (Region Taiwan Bank) (locations are shown below in Fig. 6b), where downwind (Rntwb), upwind (Rstwb), and offshore (Rtwb) flows, respectively, appear often. Since the regions Rstwb and Rntwb are very close to the coastline and shallow (on shore to the 30-m isobath; depth $h<30 \mathrm{~m}$ ), the cross-shore velocity is small $\left(\sim 5.1 \times 10^{-3} \mathrm{~m} \mathrm{~s}^{-1}\right)$ in contrast to alongshore velocity $\left(\sim 2.0 \times 10^{-1} \mathrm{~m} \mathrm{~s}^{-1}\right)$. The alongshore momentum balance (Fig. S1 in the supplemental material) shows the alongshore Coriolis terms ( $u ; u$ is the cross-shore velocity) are negligible. The dominant terms in the alongshore direction are pressure gradient (blue line), wind stress (red line), and bottom stress terms (orange line in Fig. S1) in these two near-coast regions. However, the alongshore Coriolis term is not negligible in the far-coastline region (offshore to the $30-\mathrm{m}$ isobath; $h>30 \mathrm{~m}$ ) and Rtwb region where offshore flow occurs. The Rtwb is mainly influenced by the Coriolis term plus the above three terms in the alongshore direction. In the cross-shore direction (Fig. S2), the momentums in these three regions are dominated by the pressure gradient term and the Coriolis term $f v$.

Considering barotropic dynamics for a weak stratification due to the strong winter monsoon and tides (Jan et al. 2002; Lefèvre et al. 2000; Li et al. 2006; Oey et al. 2014), a flow under surface and bottom stresses with small spatial and temporal Rossby number has the shallow-water momentum equation:

$$
\begin{aligned}
-f v & =-g \frac{\partial \eta}{\partial x}+\frac{\tau^{s x}}{H}-\frac{\tau^{b x}}{H}, \quad \text { and } \\
f u & =-g \frac{\partial \eta}{\partial y}+\frac{\tau^{s y}}{H}-\frac{\tau^{b y}}{H}
\end{aligned}
$$

Here, $x$ is cross-shore and positive in the offshore direction, and $y$ is alongshore (along the China coastline) and positive poleward. The coordinate system is shown in Fig. 1. The $H$ is the undisturbed water depth, $\eta$ is the sea level, $g$ is the acceleration due to gravity, $\mathbf{u}=(u, v)$ is the depth-averaged velocity; $\tau^{s}=\left(\tau^{s x}, \tau^{s y}\right)$ and $\tau^{b}=$ $\left(\tau^{b x}, \tau^{b y}\right)$ are kinematic surface and bottom stress vectors $\left(\mathrm{m}^{2} \mathrm{~s}^{-2}\right)$, respectively. In the near-coast regions (i.e., Rstwb and Rntwb in Fig. 6b) where $v \approx 0.2 \gg u \approx$ $0.0051 \mathrm{~m} \mathrm{~s}^{-1}$, Fig. S1 shows that surface wind stress can be balanced by the pressure gradient and bottom stress. Therefore Eq. (3.2) becomes

$$
\sigma v=-g \frac{\partial \eta}{\partial y}+\frac{\tau^{s y}}{H}
$$

Here $\boldsymbol{\tau}^{b}$ can be parameterized as $\boldsymbol{\tau}^{b}=\sigma H \mathbf{u}$, where $\sigma$ is a constant friction coefficient $\left(\sim 1.66 \times 10^{-5} \mathrm{~s}^{-1}\right.$; Oey et al. 2014). This equation indicates that the alongshore flow is driven by a balance between alongshore wind stress and sea level gradient. While the latter should strictly be treated as part of the solution, it is useful in coastal seas (Csanady 1982) to write $\eta$ as a sum of a slowly varying large-scale sea level $\eta_{0}$, which is externally imposed, and a fluctuating part $\eta^{\prime}$, which evolves as part of the flow: that is, $\eta=\eta_{0}+\eta^{\prime}$. Thus the pressuregradient acceleration likewise consists of a large-scale, externally imposed part $g \partial \eta_{0} / \partial y$ and a fluctuating part $g \partial \eta^{\prime} / \partial y$ that influences and depends on the flow u. In the Taiwan Strait, Oey et al. (2014) show that the fluctuating pressure gradient $g \partial \eta^{\prime} / \partial y$ is small compared to $g \partial \eta_{0} / \partial y$ because of, for example, the Kuroshio and/or 

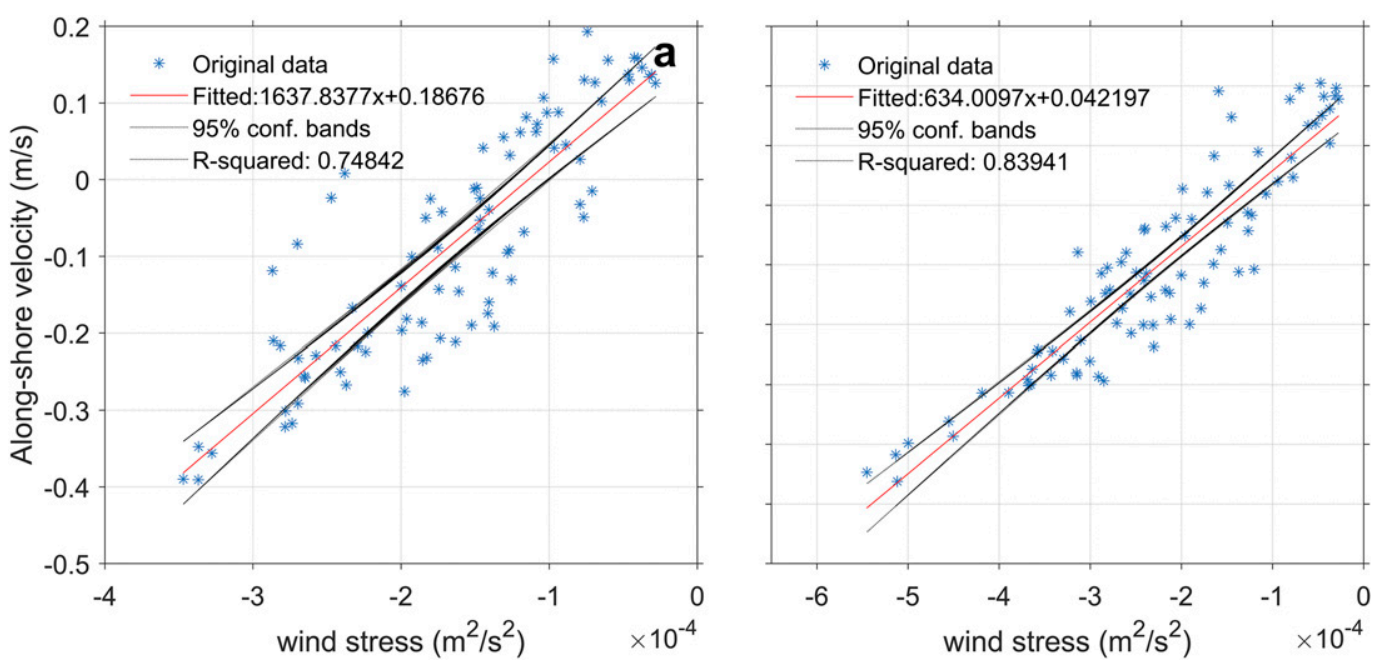

FIG. 5. The regression of regional-mean alongshore velocities $\left(\mathrm{m} \mathrm{s}^{-1}\right)$ and wind stress $\left(\mathrm{m}^{2} \mathrm{~s}^{-2}\right)$ in the regions (a) Rstwb (south TWB) and (b) Rntwb (north TWB). The red line in the middle is the linear fit and the black lines outside are the $95 \%$ confidence bands. The equation of the regressed line can be seen in the legend. Regions Rstwb and Rntwb are the black and red rectangles in Fig. 6b, respectively. These two regions represent the TWB and to north of the TWB.

warmer water of the South China Sea. Moreover, the wind varies at time scales from a few days to $1 \sim 2$ weeks, while $\eta \approx \eta_{0}$ varies at time scales of months and longer (Oey et al. 2014). The different time scales indicate that the alongshore sea level gradient can be considered as being steady compared to the wind. The large-scale forcing generally imposes a poleward pressure-gradient acceleration, $-g \partial \eta_{0} / \partial y>0$, which in winter is opposite to the acceleration due to the wind stress, $\tau^{s y} / H<0$ in the Taiwan Strait. When the northeasterly wind is stronger (weaker) than the poleward pressure gradient, the along-coast velocity is negative or equatorward (positive or poleward). On the other hand, one expects the emergence of a cross-flow, given by $u \neq 0$ but $v \approx 0$ in the region Rtwb, when the wind is moderate and the wind stress and pressure gradient terms nearly balance each other in Eq. (3.3) in Rntwb and Rstwb (cf. Oey et al. 2014).

We use the model results to regress the alongshore velocity $v$ against the alongshore wind stress $\tau^{s y}$ according to Eq. (3.4) (Oey et al. 2014):

$$
v=-\frac{g}{\sigma} \frac{\partial \eta}{\partial y}+\frac{\tau^{s y}}{\sigma H}
$$

Regressions are calculated for $v$ and $\tau^{s y}$ averaged in the near-coast regions Rstwb (Fig. 5a) and Rntwb (Fig. 5b) to the north and south of the bank. The goodness of the fit (high $r^{2}$ value: 0.75 and 0.84 ) and nonzero intercept indicate the existence and validity of $\eta \approx \eta_{0}$ as assumed a priori; the intercepts yield $(\partial \eta / \partial y)_{\text {Rstwb }} \approx-4.65 \times 10^{-7}$ and $(\partial \eta / \partial y)_{\text {Rntwb }}$ $\approx-2.72 \times 10^{-7}$. These values are comparable to those obtained in other studies (Li et al. 2018; Oey et al. 2014; Wu and Hsin 2005). It is interesting that the alongshore pressure gradient in the TWB is almost 2 times larger than that farther north in the Taiwan Strait (Li et al. 2018). Following Oey et al. (2014), we can calculate a critical wind stress $\tau_{c}^{s y}$ such that the alongshore flow is equatorward (poleward) for northeasterly wind stress stronger (weaker) than $\tau_{c}^{s y}$ (i.e., since $\tau^{s y}$ is negative): $\tau^{s y}<\tau_{c}^{s y}\left(\tau^{s y}>\tau_{c}^{s y}\right)$. Here we define $\mathrm{T}_{c n}^{s y}$ and $\mathrm{T}_{c s}^{s y}$ as wind stress criterion in the north (Rntwb) and south (Rstwb). For Rstwb, the $\tau_{c}^{s y}=\tau_{c s}^{s y} \approx-0.67 \times 10^{-4} \mathrm{~m}^{2} \mathrm{~s}^{-2}\left(\sim 7 \mathrm{~m} \mathrm{~s}^{-1}\right)$, while $\tau_{c}^{s y}=\tau_{c}^{s y} \approx-1.14 \times 10^{-4} \mathrm{~m}^{2} \mathrm{~s}^{-2}\left(\sim 9 \mathrm{~ms}^{-1}\right)$ for Rntwb. Physically, the currents at both sites Rntwb and Rstwb are equatorward for $\tau^{s y}<-1.14 \times 10^{-4} \mathrm{~m}^{2} \mathrm{~s}^{-2}$, which is sufficiently strong to overcome the poleward pressure gradient force. The currents are poleward for weak wind stress $\tau^{s y}>-0.67 \times 10^{-4} \mathrm{~m}^{2} \mathrm{~s}^{-2}$, which is overcome by the pressure gradient force; the currents are convergent with two opposite directions for intermediate wind stresses $\left(-1.14 \times 10^{-4}<\tau^{s y}<-0.67 \times 10^{-4} \mathrm{~m}^{2} \mathrm{~s}^{-2}\right)$ when the wind stress is sufficiently strong to overcome the pressure gradient force at Rntwb but is being overpowered by the stronger pressure gradient at Rstwb. In the latter, intermediate case, one expects the CCC to deflect from the coast onto the TWB.

To test these ideas, we composite the model currents according to the above critical wind stresses (Fig. 6). Despite the simplicity of the theoretical model, currents near the coast are equatorward when the wind stress is 

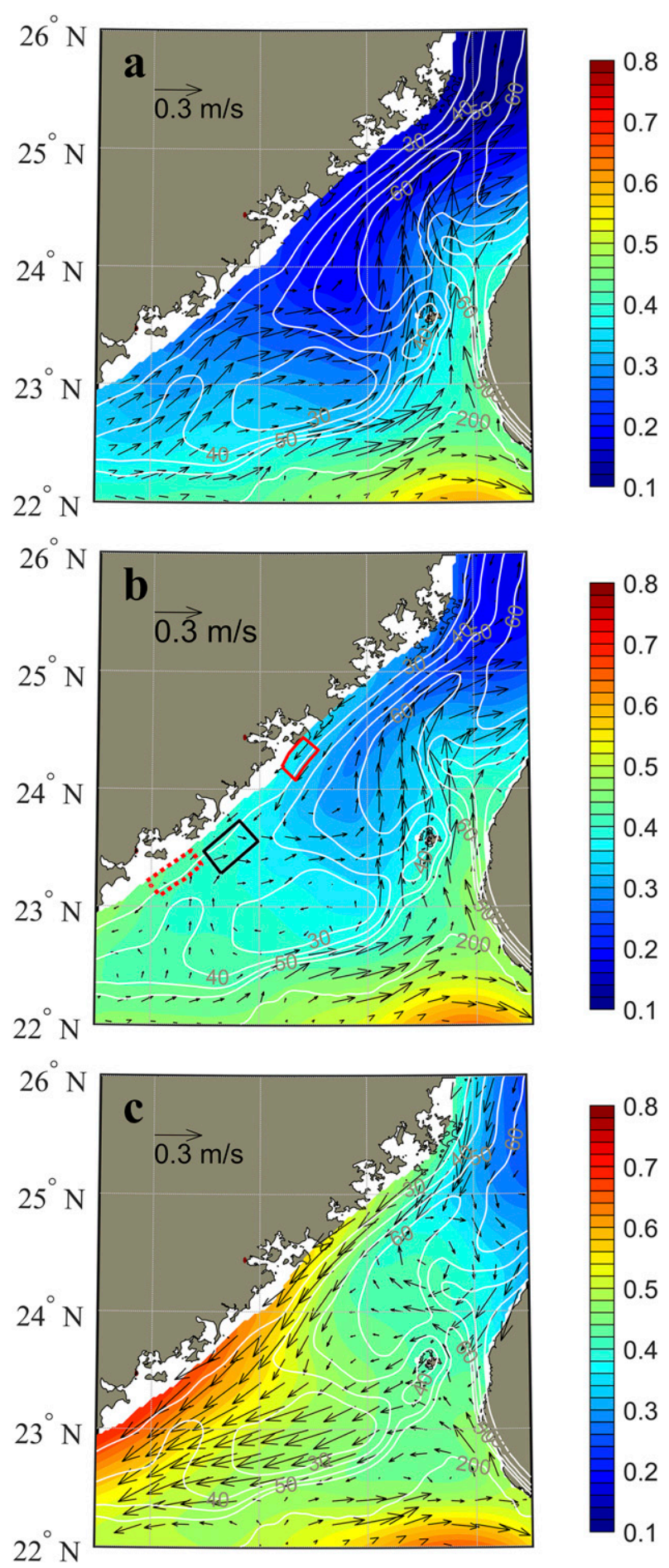

\section{$117^{\circ} \mathrm{E} \quad 118^{\circ} \mathrm{E} \quad 119^{\circ} \mathrm{E} \quad 120^{\circ} \mathrm{E}$}

FIG. 6. The mean composite patterns of sea level (color; $\mathrm{m}$ ) and depthaveraged current (vector) for (a) weak $\left(\tau^{s y}>-0.67 \times 10^{-4} \mathrm{~m}^{2} \mathrm{~s}^{-2}\right)$, (b) moderate $\left(-1.14 \times 10^{-4}<\tau^{s y}<-0.67 \times 10^{-4} \mathrm{~m}^{2} \mathrm{~s}^{-2}\right)$, and (c) strong $\left(\tau^{s y}<-1.14 \times 10^{-4} \mathrm{~m}^{2} \mathrm{~s}^{-2}\right)$ wind stress. The mean pattern is the composite mean of model results when the alongshore wind stress in different ranges. The solid red, dashed red, and solid black box in (b) are the regions Rntwb, Rstwb, and Rtwb, respectively. These three regions represent the places where the downwind flow, upwind flow, and offshore flow occur often. The white lines are the isobaths. strong $\left(\tau^{s y}<-1.14 \times 10^{-4} \mathrm{~m}^{2} \mathrm{~s}^{-2}\right.$; Fig. $\left.6 \mathrm{c}\right)$ but are poleward when the wind stress is weak $\left(\tau^{s y}>-0.67 \times\right.$ $10^{-4} \mathrm{~m}^{2} \mathrm{~s}^{-2}$; Fig. 6a). For intermediate wind stress, two oppositely directed flows converge (Fig. 6b), and a crossflow in the West Waterway appears. This is the phenomenon we often observe in winter (Figs. 2 and 3). The intermediate wind stress $\left(-1.14 \times 10^{-4}\right.$ to $-0.67 \times$ $\left.10^{-4} \mathrm{~m}^{2} \mathrm{~s}^{-2}\right)$ is close to the alongshore winter-mean wind stress $\left(-1.49 \times 10^{-4} \pm 0.84 \times 10^{-4} \mathrm{~m}^{2} \mathrm{~s}^{-2}\right.$; mean $\pm 1 \sigma)$, which explains why the coastal deflection phenomenon occurs frequently near the TWB. The occurrence criteria computed above can be verified through the relationship between chlorophyll and wind stress. The chlorophyll over the TWB tends to be maximum during the intermediate wind stress. Chlorophyll observations from 2002-15 show that high chlorophyll concentration occurs for wind stress in the range, but low for wind stress outside of the range (Fig. S3).

\section{Vorticity dynamics of the offshore flow}

The simple model above is useful, but it is linear and does not include realistic forcing and topography. To gain further insights into the relevant dynamics, we analyze the results from the ROMS simulation, focusing on December 2008 when a deflection of the China Coastal Current onto the TWB occurred (Figs. 3 and 4). In the control experiment, the surface and lateral boundary conditions of December 2008 were applied for three months. The model results in the last month are considered as being quasi steady and averaged to analyze the vorticity dynamics.

\section{a. Alongshore variation}

According to observations (Fig. 3), the cold and fresh water leaves the coast at about $23.5^{\circ} \mathrm{N}$ and spreads from the 30-m isobath to the TWB. The 30-m isobath (red line in Fig. 1) in the West Waterway is therefore selected to analyze the alongshore variability of the deflection process. The along-/cross-shore momentum balance, flow convergence/divergence, and depth-averaged velocity along this $30-\mathrm{m}$ isobath are shown in Fig. 7. The alongshore pressure gradient term (with minus sign) is positive with a peak at $23.5^{\circ} \mathrm{N}$ (Fig. $7 \mathrm{a}$ ), indicating a large-scale southward elevating sea level with a huge local increase at $23.5^{\circ} \mathrm{N}$. The large-scale sea level slope is related to the open-ocean forcing (i.e., Kuroshio), while the steep local slope at $23.5^{\circ} \mathrm{N}$ is associated with a local effect (e.g., topographic effect). Compared with the pressure gradient term, the Coriolis term $f u$ has a negative peak ( $u$ is positive, offshore) while the other terms (e.g., wind stress and bottom stress) keep flat in the separation region $\left(23.5^{\circ} \mathrm{N}\right)$. The variation of these terms 

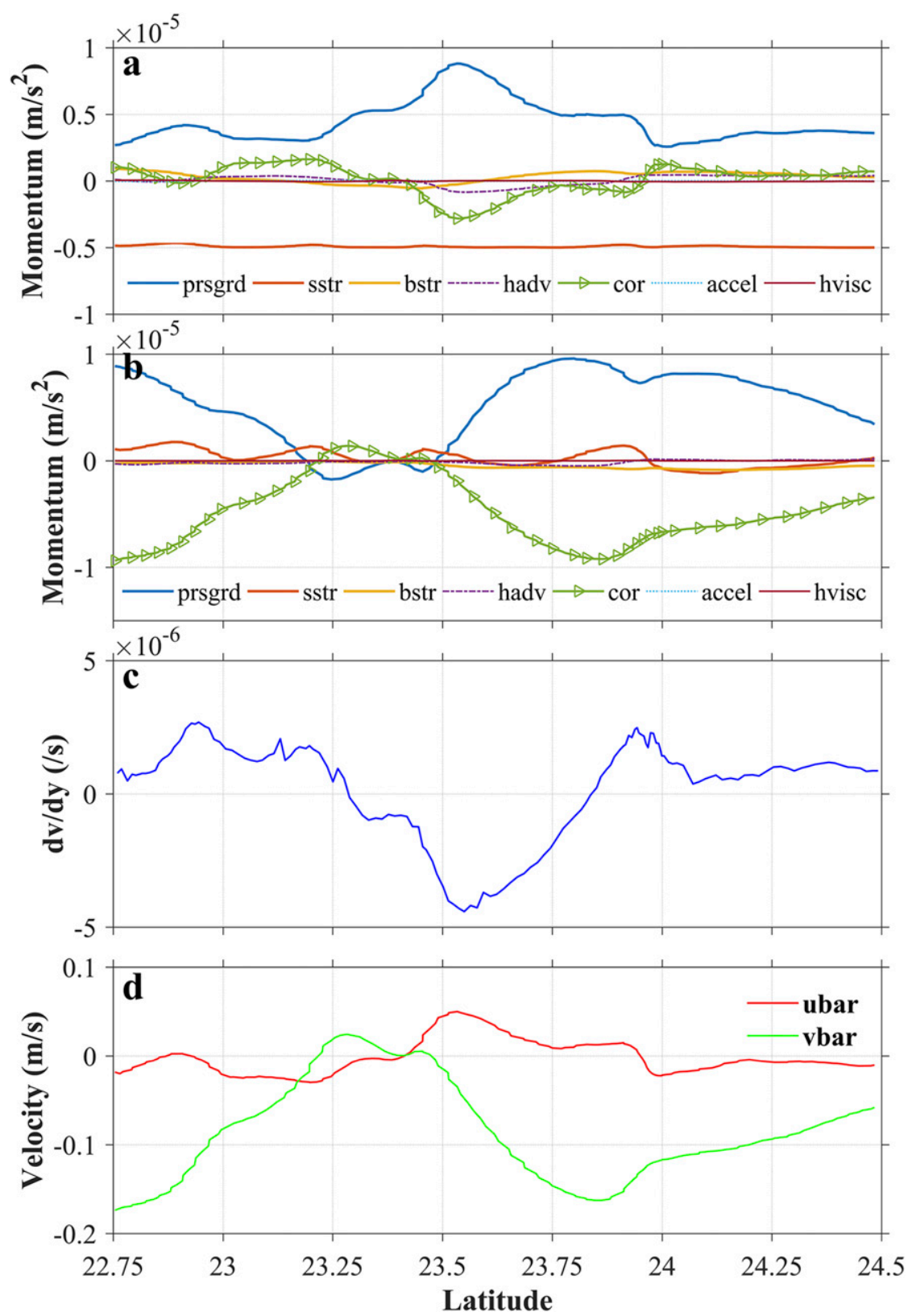

FIG. 7. The (a) alongshore and (b) cross-shore momentum balance, (c) flow convergence/ divergence indicated by $\partial v / \partial y$, and (d) depth-averaged alongshore (vbar) and cross-shore (ubar) velocities along the 30-m isobath. The prsgrd, sstr, bstr, hadv, hvisc, accel, and cor represent pressure gradient, surface wind stress, bottom stress, horizontal advection, horizontal viscosity, acceleration, and Coriolis terms, respectively. The positive values of ubar and vbar are eastward (offshore) and northward, respectively. The TWB location is between $23^{\circ}$ and $23.75^{\circ} \mathrm{N}$ and the deflection is around $23.5^{\circ} \mathrm{N}$.

(alongshore direction) along the 30-m isobath suggests that the occurrence of offshore flow is related with the huge local increase of the pressure gradient term. In other words, the offshore flow is the geostrophic current, which is further analyzed in the following section. In the cross-shore direction, the momentum balance is controlled by the pressure gradient and Coriolis term (Fig. 7b). Correspondingly, a positive (offshore) cross-shore velocity occurs near the same location $\left(23.5^{\circ} \mathrm{N}\right.$; Fig. $\left.7 \mathrm{~d}\right)$. The cross-shore velocity at other locations is weak and negative (i.e., onshore). The alongshore velocity is weak and positive (northward) in 


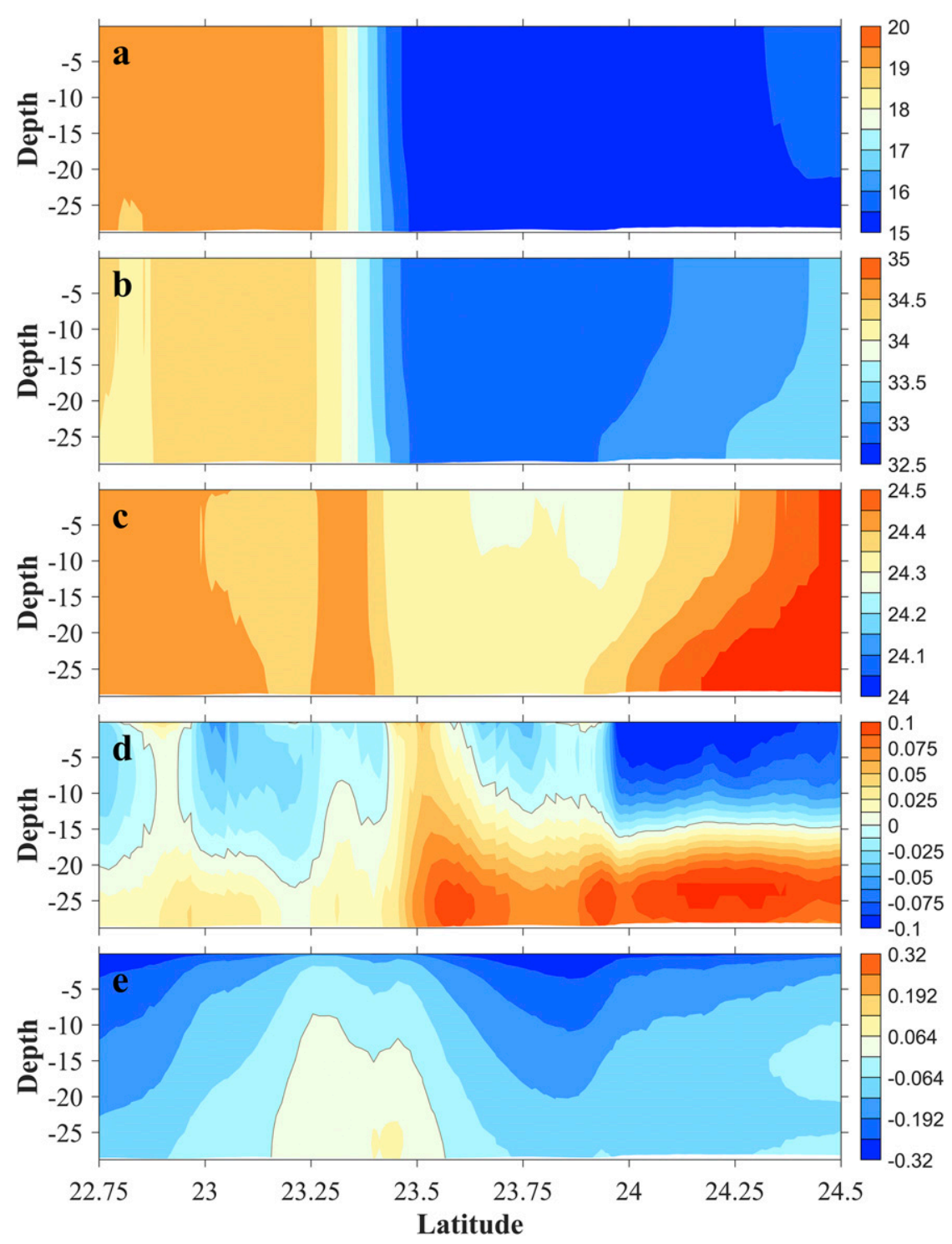

FIG. 8. The transect profiles of (a) temperature $\left({ }^{\circ} \mathrm{C}\right),(\mathrm{b})$ salinity (psu), (c) density $\left(+1000 \mathrm{~kg} \mathrm{~m}^{-3}\right)$, (d) cross-shore and (e) alongshore velocities $\left(\mathrm{m} \mathrm{s}^{-1}\right)$ along the $30-\mathrm{m}$ isobath. The positive values of velocity are eastward (offshore) and northward, respectively, for (d) and (e). The $30-\mathrm{m}$ isobath is the red line in Fig. 1. The TWB location is between $23^{\circ}$ and $23.75^{\circ} \mathrm{N}$ and the deflection is around $23.5^{\circ} \mathrm{N}$.

the TWB $\left(23^{\circ}-23.5^{\circ} \mathrm{N}\right)$ but is strong and negative (southward) to the north and south of the bank (Fig. 7d). This agrees with the flow pattern shown in Fig. 6b of two alongshore flows opposite to each other.

Corresponding to the great flow convergence by the two opposite flows near the TWB (shown by $d v / d y$ in Fig. 7c), a strong temperature and salinity front is found over the TWB, separating cold and fresh water to the north from warm and salty water in the south (Figs. 8a,b). The two different water masses indicate that the CCC does not flow past the TWB when offshore transport occurs. The temperature and salinity profiles also show a well-mixing water column, suggesting that the assumption of barotropic dynamics (weak stratification) is appropriate. However, there is a weak density gradient on the bank (Fig. 8c). The cross-shore velocity (Fig. 8d) is one layer, offshore, on the bank, but shows a two-layer flow south and north to the bank: onshore in the surface layer and offshore in the bottom layer, as in downwelling circulation driven by the northeasterly wind. The offshore velocity extends over the entire water column with decreasing magnitude from bottom 
to surface over the TWB (near $23.5^{\circ} \mathrm{N}$ ). The alongshore velocity (Fig. 8e) is strongly sheared and is negative everywhere, except near the TWB where it is negative in the upper layer but positive in the lower layer (around $23.5^{\circ} \mathrm{N}$ ). In summary, the transect profiles thus show significant alongshore variations that include a steep drop of alongshore sea level near the bank with a strong offshore velocity, a sheared and even reversing alongshore velocity, and a strong temperature and salinity gradient over the TWB. The southward coastal current (CCC) is weakened around the bank, and a reversed (northward) current (SCSWC) is produced over the bank. The dynamics determining these alongshore variations are presented next.

\section{b. Vorticity balance}

Following Oey et al. (2014), we derived a vorticity equation [Eq. (4.3)] from continuity [Eq. (4.1)] and depthaveraged momentum [Eq. (4.2)] equations to understand the effect of topography and wind and open-ocean forcing on the deflection process. The vorticity balance is analyzed in this section, and the detailed vorticity and flow fields are shown in the following section:

$$
\begin{aligned}
& \frac{\partial \eta}{\partial t}+\nabla \cdot \mathbf{u} D=0, \quad \text { and } \\
& \begin{aligned}
\frac{\partial \mathbf{u}}{\partial t} & +(\xi+f) \mathbf{k} \times \mathbf{u}+\nabla \frac{\left(|\mathbf{u}|^{2}\right)}{2} \\
& =-g \nabla \eta-\frac{g}{\rho_{0}} \frac{1}{D} \int_{-H}^{\eta} \int_{z}^{0} \nabla \rho d z^{\prime} d z+\frac{\boldsymbol{\tau}^{s}}{D}-\frac{\boldsymbol{\tau}^{b}}{D},
\end{aligned}
\end{aligned}
$$

where $\eta$ is sea level, $\mathbf{u} D$ is the transport vector per unit length, $\mathbf{u}=(u, v)$ is the depth-averaged velocity, and $D=$ $(H+\eta)$ is the total water depth. The undisturbed water depth is $H, \xi$ is the vertical component of vorticity $(\nabla \times u)$, $\mathbf{k}$ is the unit vector in the vertical direction, $f$ is the Coriolis coefficient, $\nabla$ is the horizontal gradient operator, $g$ is the gravity coefficient, $\rho$ is the density, $\rho_{0}$ is the reference density, and $z$ and $z^{\prime}$ are the depths in the vertical direction. The $\tau^{s}$ and $\tau^{b}$ are kinematic surface and bottom stress vectors $\left(\mathrm{m}^{2} \mathrm{~s}^{-2}\right)$, respectively. After taking the curl of the depth-averaged momentum equation [Eq. (4.2)], approximating both $D \approx H$ and that the flow is steady $(\partial \eta / \partial t \approx 0)$, we get the depth-averaged vorticity equation:

$$
\begin{aligned}
\underbrace{\frac{\partial \xi}{\partial t}}_{\mathrm{TR}}+\underbrace{\mathbf{u} H \cdot \nabla \frac{f}{H}}_{\mathrm{BPV}} \approx & \underbrace{-\mathbf{u} H \cdot \nabla \frac{\xi}{H}}_{\mathrm{RPV}}+\underbrace{J\left(\chi, \frac{1}{H}\right)}_{\text {JEBAR }} \\
& +\underbrace{\nabla \times \frac{\tau^{s}}{H}}_{\text {WSC }}+\underbrace{\left(-\nabla \times \frac{\tau^{b}}{H}\right)}_{\text {BSC }},
\end{aligned}
$$

where $\chi=\left(g / \rho_{0}\right) \int_{-H}^{\eta} z \rho d z^{\prime}$ and $J(A, B)=A_{x} B_{y}-A_{y} B_{x}$. To differentiate the second and third terms [advection of background potential vorticity (BPV) and advection of relative potential vorticity (RPV)] in Eq. (4.3), we define $f / H$ as background potential vorticity and $\xi / H$ as relative potential vorticity. In Eq. (4.3), on the lefthand side are the time rate (TR) term and the advection of background $\mathrm{PV}$ term, and the terms on the right-hand side are the advection of relative PV (nonlinear term), joint effect of baroclinicity and relief (JEBAR; Huthnance 1984; Mertz and Wright 1992), wind stress curl (WSC), and bottom stress curl (BSC). The time rate term is negligible for a steady flow $(\partial \xi / \partial t=0$; Fig. 9a). When the right-hand side equals zero and TR is negligible, a steady flow is along $\mathrm{flH}$ contours. The BPV is considered as an index that is positive (negative) for upslope (downslope) transport. The upslope (downslope) transport is onshore (offshore) in coastal areas where water depth deepens from coastline to open ocean. These four terms in the right-hand side represent different processes that can modify a cross-flow. The RPV $(-\mathbf{u} H \cdot \nabla(\zeta / H)$, with minus sign) is the advection of relative PV. A positive (negative) RPV is regarded as a downgradient (upgradient) advection of relative PV by the flow field. For the JEBAR $[J(\chi, 1 / H)]$, the $\chi$ is a vertical integration of density with a weight of depth and physically represents the baroclinicity. The JEBAR is considered as the combination of baroclinicity and sloping bottom topography and arises for an alongisobath density gradient. The WSC is externally imposed input of vorticity by a curl in the wind stress, while the BSC is the dissipation of vorticity by bottom friction.

These terms are plotted in Fig. 9 to determine which process or processes control the cross-flow on the TWB. Since $f$ is regarded as constant in this small region, contours of $H$ almost coincide with the $f / H$ in Fig. 9. The flow along $f / H$ contours indicates approximate geostrophic flow when BPV is very weak. Comparing with the other terms in Eq. (4.3), the TR term $(\partial \xi / \partial t)$ in Fig. 9a is negligible. The BPV has large negative values in the northern part of the West Waterway (about $23.5^{\circ} \mathrm{N}, 118^{\circ} \mathrm{E}$; black box in Fig. $9 \mathrm{~b}$ ), suggesting a strong downslope transport of the coastal current in this region where the offshore flow is observed (Figs. 2 and 3). The mean BPV in the black box (Fig. 9) is $-0.25 \times 10^{-10} \mathrm{~s}^{-2}$, while the mean BSC is $-0.42 \times 10^{-10} \mathrm{~s}^{-2}$, which indicates the negative BPV here is mainly contributed by the bottom stress curl. The RPV (nonlinear term in Fig. 9c) has a reversed effect (upslope transport) and the JEBAR term (Fig. 9d) is weak (mean is $0.018 \times$ $10^{-10} \mathrm{~s}^{-2}$ ) and positive (upslope) in this region. The reversed effect of RPV is induced by the downgradient advection of relative PV, which can be seen below in 

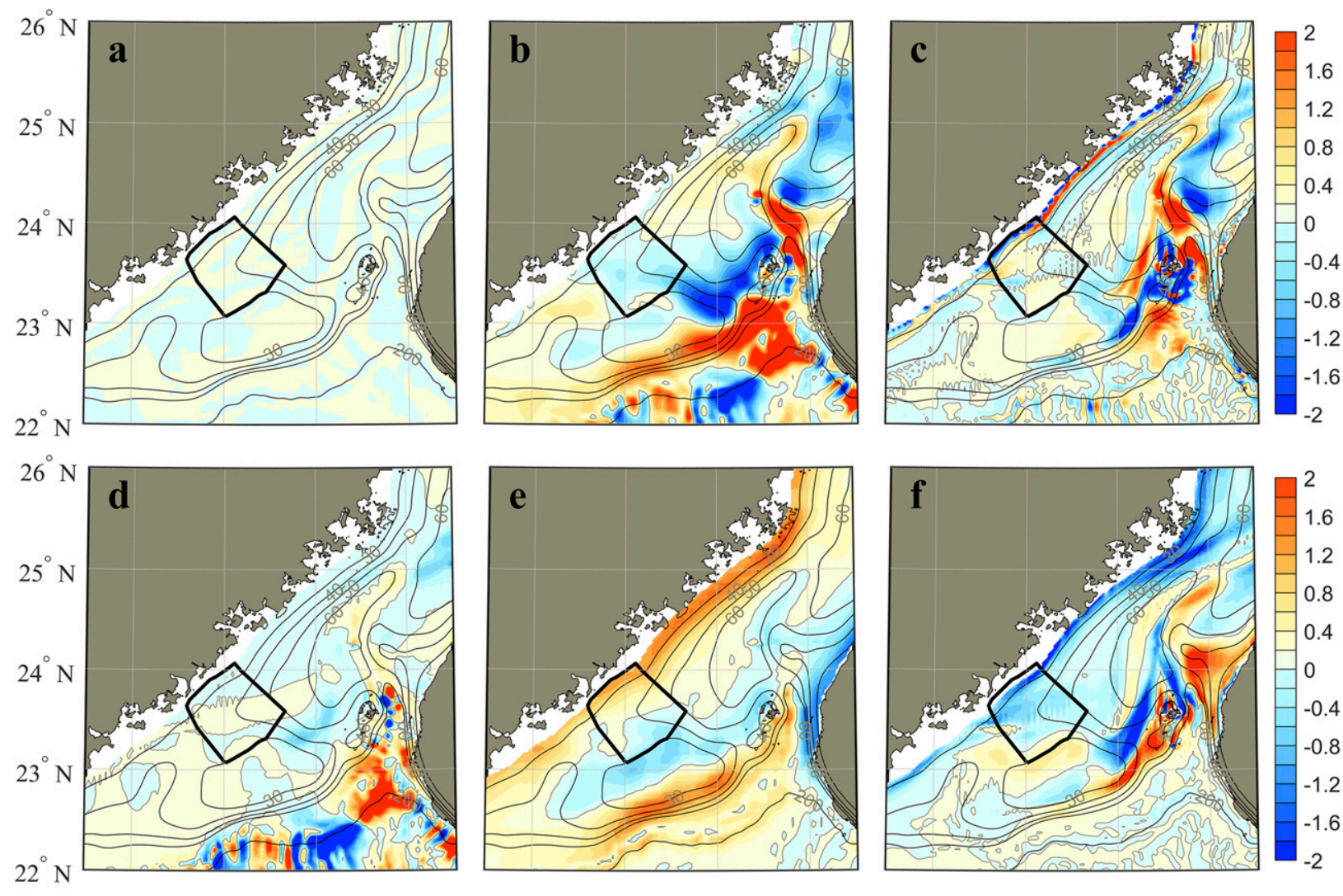

$117^{\circ} \mathrm{E} \quad 118^{\circ} \mathrm{E} \quad 119^{\circ} \mathrm{E} \quad 120^{\circ} \mathrm{E}$

$117^{\circ} \mathrm{E} \quad 118^{\circ} \mathrm{E} \quad 119^{\circ} \mathrm{E} \quad 120^{\circ} \mathrm{E}$

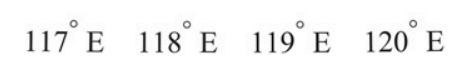

FIG. 9. The composite patterns of different terms in the vorticity equation [Eq. (4.3); $\times 10^{-10} \mathrm{~s}^{-2}$ ]. (a) TR, (b) BPV, (c) RPV, (d) JEBAR, (e) WSC, and (f) BSC in Eq. (4.3). Since $f$ is considered as constant in this small region, we plot isobaths ( $H$; black lines) to represent $f / H$. The black box is the focus region where offshore flow occurs.

Fig. 11. The weak JEBAR term is related to the weak alongshore density gradient shown in Fig. 8c. The positive WSC (Fig. 9e; mean is $0.18 \times 10^{-10} \mathrm{~s}^{-2}$ ) here has a reversed effect (upslope transport in Fig. 9f).

Along the China coast, another significant negative BPV region is around Pingtan Island in the northern Taiwan Strait (Fig. 9b). The downslope flow in this region is related to the nonlinear term in Eq. (4.3) (Oey et al. 2014). The BPV is positive (onshore flow) at other coastal areas to the north and south of the TWB, being mainly produced by the wind stress curl term in the so-called topographic- $\beta$ Sverdrup balance (Oey et al. 2014), while the curl of the bottom stress and nonlinear term nearly cancel in a thin near-coast boundary layer (Figs. 9c,f). A strong negative BPV is distributed between the Wuqiu Depression and the TWB, where it is predominantly controlled by wind stress curl and bottom stress curl. Since water depth shallows from west to east in this region, wind stress curl induces a negative value (westward and downslope flow) in this region. In the eastern TWB, an upslope flow (positive BPV) is strengthened by the nonlinear term, wind stress curl, and bottom stress curl. The outer shelf and shelf break $(>100 \mathrm{~m})$ are dominated by the JEBAR term (Fig. 9d). The reason for such a large JEBAR effect here may be tied to a strong density gradient produced by the cold water in the strait and warm water from the south.

\section{c. The along-isobath balance}

To further examine the cross-flow, we examine the vorticity equation [Eq. (4.3)] along the 30-m isobath. Since the $30-\mathrm{m}$ isobath is almost parallel to the shoreline, the coordinate system is the same as before. The BPV $[\mathbf{u} H \nabla(f / H)]$ is written as $u H(\partial / \partial x)(f / H)+v H(\partial / \partial y)(f / H)$, and the second part $[v H(\partial / \partial y)(f / H)]$ is ignored along the isobath $(y$ direction) on an $f$ plane. The $f$ is considered constant in such a small region. The first part $[u H(\partial / \partial x)(f / H)]$ remains on the left side and the cross-isobath velocity $u$ is then linked to the vorticity dynamics after dividing by $H(\partial / \partial x)(f / H)$ : 


$$
\begin{aligned}
u \approx & \underbrace{\frac{H}{f H_{x}}\left(\mathbf{u} H \cdot \nabla \frac{\xi}{H}\right)}_{u_{\mathrm{RPV}}}-\underbrace{\frac{H}{f H_{x}} J\left(\chi, \frac{1}{H}\right)}_{u_{\mathrm{JEBAR}}} \\
& -\underbrace{\frac{H}{f H_{x}}\left(\nabla \times \frac{\boldsymbol{\tau}^{s}}{H}\right)}_{u_{\mathrm{WSC}}}+\underbrace{\frac{H}{f H_{x}}\left(\nabla \times \frac{\boldsymbol{\tau}^{b}}{H}\right)}_{u_{\mathrm{BSC}}},
\end{aligned}
$$

where $H_{x}$ is the partial differentiation of depth normal to the isobaths (bathymetry slope). The cross-isobath velocity in Eq. (4.4) is produced by four processes, which are RPV, JEBAR, WSC, and BSC. These terms along the 30-m isobath are shown in Fig. 10a. The intensified offshore flow in the bank (positive $u_{\text {all }}$ around $23.5^{\circ} \mathrm{N}$ ) is evidently induced by the $u_{\mathrm{BSC}}$ as noted previously in Fig. 9. The $u_{\mathrm{BSC}}$ increases gradually from $24^{\circ} \mathrm{N}$ upstream (north) of the bank and reaches a maximum at $23.5^{\circ} \mathrm{N}$, and the $u_{\mathrm{RPV}}$ has a reversed pattern, while the $u_{\mathrm{WSC}}$ and $u_{\mathrm{JEBAR}}$ keep flat along the $30-\mathrm{m}$ isobaths. The increase of $u_{\mathrm{BSC}}$ overcomes the other three terms leading to a positive velocity in the bank. The increase of $u_{\mathrm{BSC}}$ is related to the gentle slope and strengthened relative vorticity, which are further analyzed following. Both $u_{\mathrm{BSC}}$ and $u_{\mathrm{RPV}}$ weaken rapidly to the south of $23.5^{\circ} \mathrm{N}$ where the $u_{\mathrm{WSC}}$ is again dominant. Except for the TWB, the cross-isobath velocity in other areas is primarily driven by the wind stress curl.

To examine the bottom stress curl in detail, we split this term into three components [Eq. (4.5)] according to $\tau_{b}=C_{d}\left|\mathbf{u}_{b}\right| \mathbf{u}_{b}$, where $\mathbf{u}_{b}$ is the bottom velocity and $\left|\mathbf{u}_{b}\right|$ is the magnitude of the bottom velocity:

$$
\begin{aligned}
u_{\mathrm{BSC}}= & \frac{H}{f H_{x}} \nabla \times \frac{\tau^{b}}{H}=\underbrace{\frac{C_{d}\left|\mathbf{u}_{b}\right|}{f H_{x}} \nabla \times \mathbf{u}_{b}}_{\text {I }} \\
& +\underbrace{\frac{H}{f H_{x}} C_{d}\left|\mathbf{u}_{b}\right| \nabla H^{-1} \times \mathbf{u}_{b}}_{\text {II }}+\underbrace{\frac{C_{d}}{f H_{x}} \nabla\left|\mathbf{u}_{b}\right| \times \mathbf{u}_{b}}_{\text {III }},
\end{aligned}
$$

where $u_{\mathrm{BSC}}$ is the cross-isobath velocity induced by the bottom stress curl and $C_{d} \approx 2.5 \times 10^{-3}$ is the bottom drag coefficient. Equation (4.5) indicates that the $u_{\mathrm{BSC}}$ is attributed to three processes (terms I, II, and III). Term I is the cross-flow caused by frictional dissipation of the vorticity. If the flow has positive relative vorticity, the effect of friction is to cause a downslope (offshore) velocity as the parcel moves to a region with lower background PV, and vice versa for negative vorticity, which then induces an upslope (onshore) velocity. The crossisobath velocity induced by this term (I) is in geostrophic balance with an along-isobath pressure gradient (see supplemental material). Term II is described as a "drag torque" by Oey et al. (2014), and can be further expressed as $C_{d}\left|\mathbf{u}_{b}\right| v_{b} / f$, which is the bottom Ekman transport. The velocity caused by this term is confined in the bottom Ekman depth. Term III is considered as the "speed torque" by Oey et al. (2014) and represents a similar physical process of term I that this term is also geostrophic and extends through the water column. However, this term only involves shear vorticity, and the term I includes shear and curvature vorticity (Liu and Gan 2014; Oey et al. 2014). The shear vorticity depends on a spatial variation of flow field, and the curvature vorticity is only associated with the curving streamline. In addition to the relative vorticity, the magnitudes of terms I and III are amplified by a gentler slope $H_{x}$ in Eq. (4.5) over the TWB. If Eq. (4.5) is multiplied by $f$, Gan et al. (2013) stated that terms I and III, related to local topography, induce a locally along-isobath pressure gradient, which is derived in appendix S2 in the supplemental material. The peaks of terms I and III (Fig. 10b) in the bank are consistent with the sharp increase of sea level in Fig. 7a. This confirms the cross-isobath velocity induced by terms I and III are in geostrophic balance with the alongshore sea level gradient.

The relative strength of each term in Eq. (4.5) is plotted in Fig. 10b. The $u_{\mathrm{BSC}}$ is mainly contributed to by terms I and III. The bottom Ekman transport term (II) contributes little. Term I slowly increases at $24^{\circ} \mathrm{N}$, while term III grows rapidly in the northern TWB $\left(23.5^{\circ}-24^{\circ} \mathrm{N}\right)$ and decays fast in the southern side. The dominance of terms I and III clearly demonstrates a tight relation between this offshore flow and the relative vorticity and slope. Figure 10c reveals a decline of slope and an increase of relative vorticity at $23.5^{\circ} \mathrm{N}$. This suggests both slope and vorticity contribute to the reinforcement of the bottom stress curl here. Note that the contribution of the slope decline seems more than the relative vorticity based on their ratio changes. The slope is about $8 \times 10^{-4}$ to the north of the bank and decreases to as low as $1 \times 10^{-4}$ at $23.5^{\circ} \mathrm{N}$ in the bank. To the south of $23.5^{\circ} \mathrm{N}$, the slope increases to $5.8 \times 10^{-4}$ around $23.1^{\circ} \mathrm{N}$ and then falls to $4 \times 10^{-4}$. The relative vorticity decreases from $0.2 f$ to $0.1 f$ to the north of the bank and increases to as large as $0.21 f$ in the bank. The vorticity is zero at $23.4^{\circ} \mathrm{N}$ where velocity is zero, shown in Fig. $7 \mathrm{c}$. To the south of the bank, the vorticity varies between $0.1 f$ and $0.2 f$. Through Eqs. (4.3) and (4.5), the mechanism can be explained such that a flow with a positive relative vorticity results in a negative bottom stress curl for friction removal. This negative bottom stress curl is strengthened at a gentle slope in the TWB, which induces an enhanced offshore current over the bank. From another point of view (Gan et al. 2013), the 

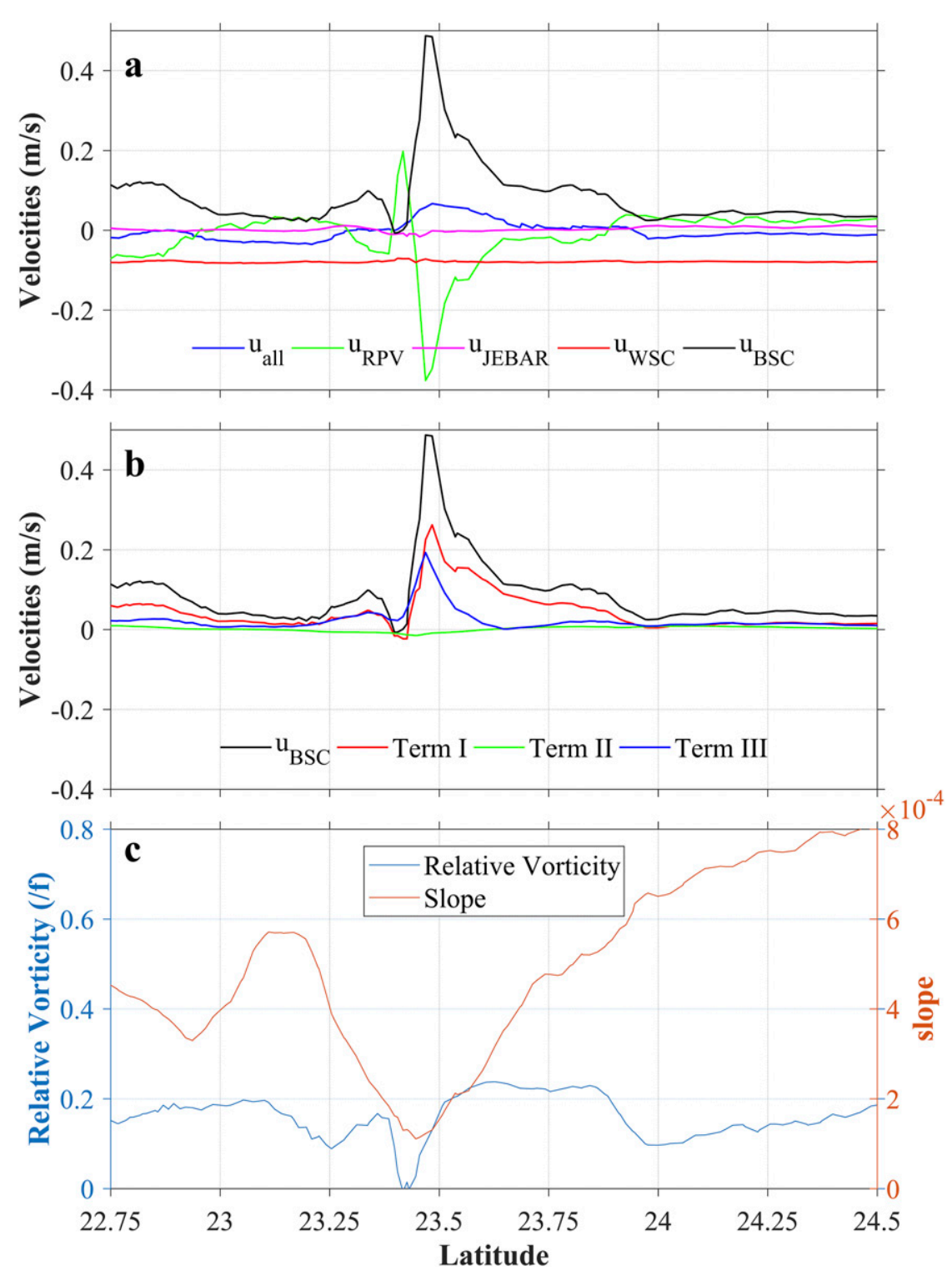

FIG. 10. (a) The overall cross-isobath velocity $u_{\text {all }}$ and the cross-isobath velocities caused by different terms according to Eq. (4.4). (b) The cross-isobath velocities induced by bottom stress curl and its three components according to Eq. (4.5). (c) The relative vorticity (blue) and slope (red) along the $30-\mathrm{m}$ isobath. The relative vorticity is normalized by the Coriolis coefficient $f$. All three panels are plotted along the $30-\mathrm{m}$ isobath (the red line in Fig. 1). The TWB location is between $23^{\circ}$ and $23.75^{\circ} \mathrm{N}$ and the deflection is around $23.5^{\circ} \mathrm{N}$.

offshore flow is regulated by the dynamics related to the locally alongshore pressure gradient generated by the local topography.

\section{d. Numerical experiments}

As shown above, the strong positive vorticity and weak slope result in the offshore flow in the TWB. The vorticity depends on flow field, which is modified by topography, the northeasterly monsoon wind, and open-ocean forcing. We wish to understand how they are related. Numerical experiments are conducted to investigate their relationship (Table 1). The gentle slope and vorticity associated with two alongshore flows opposite to each other are included in the control case. In the second (wind only) and third [northward pressure gradient (NPG) only] cases, only one forcing is considered and one alongshore flow is produced, which indicates a reduced vorticity over the TWB. These two 
TABLE 1. The experiment descriptions.

\begin{tabular}{ll}
\hline \multicolumn{1}{c}{ Case names } & \multicolumn{1}{c}{ Descriptions } \\
\hline $\begin{array}{l}\text { Control case } \\
\text { Wind only }\end{array}$ & $\begin{array}{c}\text { Dynamic analysis } \\
\text { NPG at the lateral boundary is removed } \\
\text { in the find-grid model. } \\
\text { WPG only }\end{array}$ \\
$\begin{array}{l}\text { Wind is removed in the fine-grid model. } \\
\text { The Taiwan Bank (gentle slope) is removed } \\
\text { in the fine-grid model. }\end{array}$ \\
\hline
\end{tabular}

cases study the influence of vorticity on the offshore flow. The fourth case keeps the two forcings but removes the TWB (gentle slope at $23.5^{\circ} \mathrm{N}$ ) by smoothing the topography in the fine grid. This case studies the relationship between the gentle slope and offshore flow. The slope along the $30-\mathrm{m}$ isobath ranges from $4 \times 10^{-4}$ to $6 \times 10^{-4}$ in the non-TWB case, while it varies between $1 \times 10^{-4}$ and $8 \times 10^{-4}$ in the control case.

The depth-averaged current and relative vorticity of all experiments are plotted in Fig. 11. An apparent crossflow occurs in only the control case (Fig. 11a), which suggests the topography and both forces all play an important role. In the control case, a stripe of positive vorticity is seen along the coast and enlarges in the West Waterway. The stripe also emerges in the non-TWB case (Fig. 11d) but disappears in the cases with only one force (i.e., wind only and NPG only; Figs. 11b and 11c). This indicates the stripe of positive vorticity is related to the concurrence of two opposite currents (i.e., the coastal current attached along the coastline and the SCSWC in the shelf). However, this stripe of positive vorticity alone leads to a weak cross-flow without a
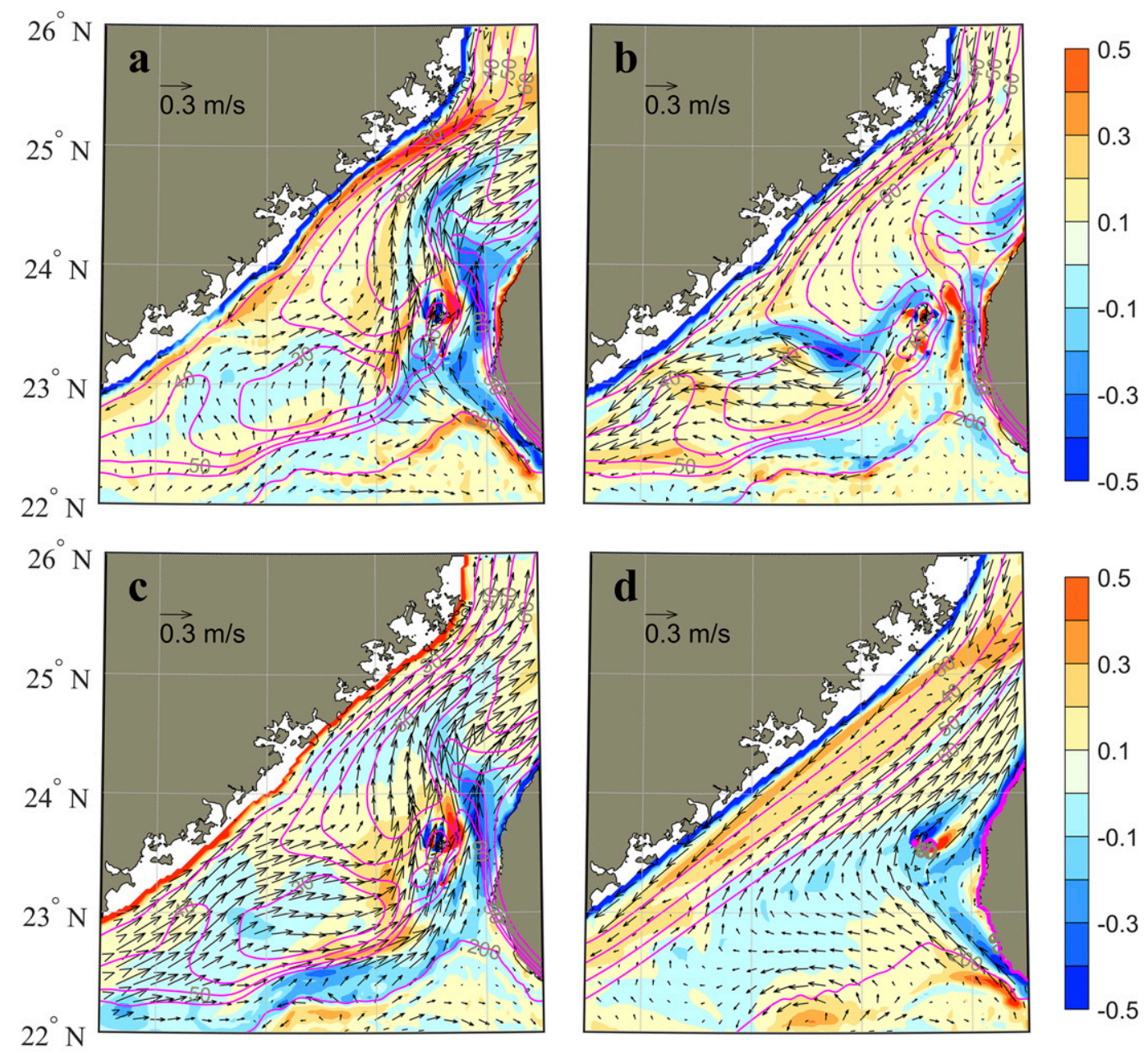

$117^{\circ} \mathrm{E} \quad 118^{\circ} \mathrm{E} \quad 119^{\circ} \mathrm{E} \quad 120^{\circ} \mathrm{E}$

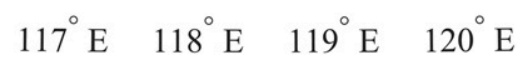

FIG. 11. The composite patterns of depth-averaged relative vorticity (shading) and currents (arrows) in the experiments. (a) The control case, (b) wind only, (c) NPG only, and (d) the non-TWB case. The pink lines are the isobaths from 30 to $60 \mathrm{~m}$. The relative vorticity is normalized by the Coriolis coefficient $\xi / f$. 
gentle slope in the non-TWB case (Fig. 11d). The apparent cross-flow in the control case suggests this also needs the contribution of a gentle slope around $23.5^{\circ} \mathrm{N}$. In the wind-only and NPG-only cases, a gentle slope exists but a large positive vorticity vanishes, and there is no evident cross-flow in the West Waterway $\left(23.5^{\circ} \mathrm{N}\right)$. These experiments suggest that the cross-flow is associated with a gentle slope (TWB) and two externalopposite forces: wind (northeasterly monsoon) and NPG (open-ocean sea level gradient) force. The generating process of cross-flow is that the two external forces (wind and NPG) opposite to each other first drive a southward coastal current along the coastline and a northward current (SCSWC) in the shelf. Then the two opposite currents form an increased positive vorticity over the TWB. This increased positive vorticity plus the gentle slope causes an amplified cross-flow in the bank.

\section{Conclusions}

This study provides evidence of and explains the cold water deflection in winter over the TWB using observations and models. The cold and fresh coastal current leaves the $30-\mathrm{m}$ isobath at $23.5^{\circ} \mathrm{N}$, crosses the West Waterway, and spreads from the coast to the Central Bank. The chlorophyll shows high concentration in the same region, in agreement with the temperature and salinity distributions. The separated, nutrient-rich coastal water is important to the marine ecosystem and fishery. Model simulation and analyses are conducted to understand the deflection process and associated mechanisms.

Three circulation regimes are derived depending on the balance of wind stress and pressure gradient associated with the poleward tilt of sea level along the Taiwan Strait. The flow is controlled by a southward (northward) current when the wind stress is stronger (weaker) than an upper (lower) bound. The two alongshore flows with opposite directions occur simultaneously, and the coastal current deflects when the wind stress is moderate.

There is a striking alongshore variation around $23.5^{\circ} \mathrm{N}$ along the $30-\mathrm{m}$ isobath. The southward coastal current is weakened in the TWB, and a reversed (northward) current is generated over this bank. Associated with this two-flow concurrence, an offshore transport is strengthened and large temperature and salinity gradients are formed over the bank.

Vorticity analysis and numerical experiments indicate that the offshore transport is associated with two factors: the gentle slope and increased positive vorticity. The gentle slope is related with the bank area (TWB). The increased positive vorticity is induced by two opposite flows driven by two external forces: wind (northeasterly monsoon) and open-ocean sea level gradient (NPG; pointing northward; see the experiment in Table 1). Over the TWB, the northeasterly monsoon drives a southward coastal current along the coastline and the open-ocean forcing induces a northward warm current (SCSWC) on the shelf. These two currents meet at the western bank, with the former limited to the inner shelf and latter located on the outer shelf, generating a strong relative vorticity. The high relative vorticity triggers a negative bottom stress curl, which is reinforced in the bank by the gentle slope over the bank. This reinforced negative bottom stress curl dominates the other terms in Eq. (4.3) and leads to an amplified offshore flow over the bank. The numerical experiments verify the vorticity analysis that the offshore flow is only generated in the control case including both the slope and high relative vorticity.

Acknowledgments. This work was supported by a grant (U1305231) from the Natural Science Foundation of China (NSFC) and Fujian Province and the SOA Global Change and Air-Sea Interaction Project (GASI-IPOVAI-01-04). We also thank the NSFC (Grants 41630963 and 41476005) and NASA (Grant NNX15AI19H from the Delaware Space Grant College and Fellowship Program) for financial support. The authors thank NOAA/NODC for the SST and chlorophyll data and REMSS for the CCMP wind data used in this research. We thank the editor and two anonymous reviewers for the valuable comments. The help from J. R. Sun in plotting the figures is appreciated.

\section{REFERENCES}

Barnier, B., L. Siefridt, and P. Marchesiello, 1995: Thermal forcing for a global ocean circulation model using a three-year climatology of ECMWF analyses. J. Mar. Syst., 6, 363-380, https://doi.org/10.1016/0924-7963(94)00034-9.

Chapman, D. C., 1985: Numerical treatment of cross-shelf open boundaries in a barotropic coastal ocean model. J. Phys. Oceanogr., 15, 1060-1075, https://doi.org/10.1175/1520-0485 (1985)015<1060:NTOCSO > 2.0.CO;2.

Chen, Z., X.-H. Yan, and Y. Jiang, 2014: Coastal cape and canyon effects on wind-driven upwelling in northern Taiwan Strait. J. Geophys. Res. Oceans, 119, 4605-4625, https://doi.org/ 10.1002/2014JC009831.

Csanady, G. T., 1982: Circulation in the Coastal Ocean. Springer, $281 \mathrm{pp}$.

Egbert, G. D., and S. Y. Erofeeva, 2002: Efficient inverse modeling of barotropic ocean tides. J. Atmos. Oceanic Technol., 19 , 183-204, https://doi.org/10.1175/1520-0426(2002)019<0183: EIMOBO $>2.0 . \mathrm{CO} ; 2$.

Flather, R. A., 1987: A tidal model of the northeast Pacific. Atmos.Ocean, 25, 22-45, https://doi.org/10.1080/07055900.1987. 9649262 . 
Gan, J., H. San Ho, and L. Liang, 2013: Dynamics of intensified downwelling circulation over a widened shelf in the northeastern South China Sea.J. Phys. Oceanogr., 43, 80-94, https:// doi.org/10.1175/JPO-D-12-02.1.

Gong, Y., R. He, G. G. Gawarkiewicz, and D. K. Savidge, 2015: Numerical investigation of coastal circulation dynamics near Cape Hatteras, North Carolina, in January 2005. Ocean Dyn., 65, 1-15, https://doi.org/10.1007/s10236-014-0778-6.

Guan, B. X., and G. H. Fang, 2006: Winter counter-wind currents off the southeastern China coast: A review. J. Oceanogr., 62, 1-24, https://doi.org/10.1007/s10872-006-0028-8.

Gula, J., M. J. Molemaker, and J. C. McWilliams, 2015: Gulf Stream dynamics along the southeastern U.S. seaboard. J. Phys. Oceanogr., 45, 690-715, https://doi.org/10.1175/ JPO-D-14-0154.1.

Hong, H. S., F. Chai, C. Y. Zhang, B. Q. Huang, Y. W. Jiang, and J. Y. Hu, 2011: An overview of physical and biogeochemical processes and ecosystem dynamics in the Taiwan Strait. Cont. Shelf Res., 31 (Suppl.), S3-S12, https://doi.org/10.1016/ j.csr.2011.02.002.

Hsieh, H. J., Y. L. Hsien, M. S. Jeng, W. S. Tsai, W. C. Su, and C. A. Chen, 2008: Tropical fishes killed by the cold. Coral Reefs, 27, 599, https://doi.org/10.1007/s00338-008-0378-3.

Hu, J. Y., H. S. Hong, Z. Z. Chen, Z. G. He, J. S. Hong, and H. X. Liang, 1999: Analysis on feature of temperature and salinity in the northern Taiwan Straits during FebruaryMarch, 1998 (in Chinese). Mar. Sci. Bull., 1, 69-75.

—, H. Kawamura, C. Y. Li, H. S. Hong, and Y. W. Jiang, 2010: Review on current and seawater volume transport through the Taiwan Strait. J. Oceanogr., 66, 591-610, https://doi.org/ 10.1007/s10872-010-0049-1.

Huang, R. X., 1989: Characteristics of water temperature and salinity in north central Taiwan Strait (in Chinese). Mar. Sci., 6, 33-38.

Huthnance, J. M., 1984: Slope currents and “JEBAR." J. Phys. Oceanogr., 14, 795-810, https://doi.org/10.1175/1520-0485(1984) 014<0795:SCA > 2.0.CO;2.

Jan, S., and S. Y. Chao, 2003: Seasonal variation of volume transport in the major inflow region of the Taiwan Strait: The Penghu Channel. Deep-Sea Res. II, 50, 1117-1126, https:// doi.org/10.1016/S0967-0645(03)00013-4.

_- J. Wang, C. S. Chern, and S. Y. Chao, 2002: Seasonal variation of the circulation in the Taiwan Strait. J. Mar. Syst., 35, 249-268, https://doi.org/10.1016/S0924-7963(02)00130-6.

Lee, M.-A., Y.-C. Yang, Y.-L. Shen, Y. Chang, W.-S. Tsai, K.-W. Lan, and Y.-C. Kuo, 2014: Effects of an unusual cold-water intrusion in 2008 on the catch of coastal fishing methods around Penghu Islands, Taiwan. Terr. Atmos. Ocean. Sci., 25, 107-120, https://doi.org/10.3319/TAO.2013.08.06.01(Oc).

Lefèvre, F., C. Le Provost, and F. H. Lyard, 2000: How can we improve a global ocean tide model at a regional scale? A test on the Yellow Sea and the East China Sea. J. Geophys. Res., 105, 8707-8725, https://doi.org/10.1029/1999JC900281.

Li, C., J. Hu, S. Jan, Z. Wei, G. Fang, and Q. Zheng, 2006: Winterspring fronts in Taiwan Strait. J. Geophys. Res., 111, C11S13, https://doi.org/10.1029/2005JC003203.

Li, L., X. G. Guo, E. H. Liao, and Y. W. Jiang, 2018: Subtidal variability in the Taiwan Strait induced by combined forcing of winter monsoon and topography. Sci. China Earth Sci., 61, 483493, https://doi.org/10.1007/s11430-016-9132-9.

Liao, E. H., Y. W. Jiang, L. Li, H. S. Hong, and X. H. Yan, 2013a: The cause of the 2008 cold disaster in the Taiwan Strait. Ocean Modell., 62, 1-10, https://doi.org/10.1016/j.ocemod.2012.11.004.
,-- X. X. Yan, Z. Y. Chen, J. Wang, and L. P. Zhang, 2013b: Allocation of marine environmental carrying capacity in the Xiamen Bay. Mar. Pollut. Bull., 75, 21-27, https://doi.org/ 10.1016/j.marpolbul.2013.08.023.

- W. F. Lu, X.-H. Yan, Y. W. Jiang, and A. Kidwell, 2015: The coastal ocean response to the global warming acceleration and hiatus. Sci. Rep., 5, 16630, https://doi.org/10.1038/srep16630.

_, X.-H. Yan, and Y. Jiang, 2017: The role of coastal-trapped waves on the 2008 cold disaster in the Taiwan Strait. Ocean Dyn., 67, 611-619, https://doi.org/10.1007/s10236-017-1042-7.

Lin, S. F., T. Y. Tang, S. Jan, and C. J. Chen, 2005: Taiwan Strait Current in winter. Cont. Shelf Res., 25, 1023-1042, https:// doi.org/10.1016/j.csr.2004.12.008.

Lin, X., X.-H. Yan, Y. Jiang, and Z. Zhang, 2016: Performance assessment for an operational ocean model of the Taiwan Strait. Ocean Modell., 102, 27-44, https://doi.org/10.1016/ j.ocemod.2016.04.006.

Liu, Z., and J. Gan, 2014: Modeling study of variable upwelling circulation in the East China Sea: Response to a coastal promontory. J. Phys. Oceanogr., 44, 1078-1094, https:// doi.org/10.1175/JPO-D-13-0170.1.

Lu, W., X.-H. Yan, and Y. Jiang, 2015: Winter bloom and associated upwelling northwest of the Luzon Island: A coupled physical-biological modeling approach. J. Geophys. Res. Oceans, 120, 533-546, https://doi.org/10.1002/2014JC010218.

Mellor, G. L., and T. Yamada, 1982: Development of a turbulence closure model for geophysical fluid problems. Rev. Geophys., 20, 851-875, https://doi.org/10.1029/RG020i004p00851.

— L L. Y. Oey, and T. Ezer, 1998: Sigma coordinate pressure gradient errors and the seamount problem. J. Atmos. Oceanic Technol., 15, 1122-1131, https://doi.org/10.1175/1520-0426 (1998)015<1122:SCPGEA >2.0.CO;2.

Mertz, G., and D. G. Wright, 1992: Interpretations of the JEBAR term. J. Phys. Oceanogr., 22, 301-305, https://doi.org/10.1175/ 1520-0485(1992)022<0301:IOTJT>2.0.CO;2.

Oey, L.-Y., Y.-C. Hsin, and C.-R. Wu, 2010: Why does the Kuroshio northeast of Taiwan shift shelfward in winter? Ocean Dyn., 60, 413-426, https://doi.org/10.1007/s10236-0090259-5.

- M. C. Chang, Y. L. Chang, Y. C. Lin, and F. H. Xu, 2013: Decadal warming of coastal China seas and coupling with winter monsoon and currents. Geophys. Res. Lett., 40, 62886292, https://doi.org/10.1002/2013GL058202.

—, Y. L. Chang, Y. C. Lin, M. C. Chang, S. Varlamov, and Y. Miyazawa, 2014: Cross flows in the Taiwan Strait in winter. J. Phys. Oceanogr., 44, 801-817, https://doi.org/10.1175/JPOD-13-0128.1.

Pan, A. J., X. F. Wan, X. G. Guo, and C. S. Jing, 2013: Responses of the Zhe-Min coastal current adjacent to Pingtan Island to the wintertime monsoon relaxation in 2006 and its mechanism. Sci. China Earth Sci., 56, 386-396, https://doi.org/10.1007/ s11430-012-4429-9.

Qiu, Y., J. D. Xu, X. G. Guo, N. Lin, and X. W. Zhou, 2012: Temperature inversion in the Taiwan Strait during northeast monsoon. Acta Oceanogr. Sin., 34, 13-22.

Shao, H., Y. Li, and L. Li, 2011: Sun glitter imaging of submarine sand waves on the Taiwan Banks: Determination of the relaxation rate of short waves. J. Geophys. Res., 116, C06024, https://doi.org/10.1029/2010JC006798.

Shchepetkin, A. F., and J. C. McWilliams, 2003: A method for computing horizontal pressure-gradient force in an oceanic model with a nonaligned vertical coordinate. J. Geophys. Res., 108, 3090, https://doi.org/10.1029/2001JC001047. 
and — 2005: The Regional Oceanic Modeling System (ROMS): A split-explicit, free-surface, topography-followingcoordinate oceanic model. Ocean Modell., 9, 347-404, https:// doi.org/10.1016/j.ocemod.2004.08.002.

Tang, H. G., 1978: The situations and reviews of the mass mortalities due to freeze during winter time in Pescadores (in Chinese). China Fish Mon., 302, 24-26.

Wang, J., and L. Y. Oey, 2016: Seasonal exchanges of the Kuroshio and shelf waters and their impacts on the shelf currents of the East China Sea. J. Phys. Oceanogr., 46, 1615-1632, https:// doi.org/10.1175/JPO-D-15-0183.1.

— H. Hong, Y. Jiang, F. Chai, and X.-H. Yan, 2013: Summer nitrogenous nutrient transport and its fate in the Taiwan Strait: A coupled physical-biological modeling approach. J. Geophys. Res. Oceans, 118, 4184-4200, https://doi.org/ $10.1002 /$ jgrc. 20300.

,-- , and -2016 : A coupled physical-biological modeling study of the offshore phytoplankton bloom in the Taiwan Strait in winter. J. Sea Res., 107, 12-24, https://doi.org/10.1016/ j.seares.2015.11.004.

Whitney, M. M., and J. S. Allen, 2009: Coastal wind-driven circulation in the vicinity of a bank. Part I: Modeling flow over idealized symmetric banks. J. Phys. Oceanogr., 39, 1273-1297, https://doi.org/10.1175/2008JPO3966.1.

Wu, B. Y., 1982: Climatic characteristics of the Taiwan Strait (in Chinese). J. Oceanogr. Taiwan Strait, 1, 15-18.

Wu, C. R., and Y. C. Hsin, 2005: Volume transport through the Taiwan Strait: A numerical study. Terr. Atmos. Oceanic Sci., 16, 377-391, https://doi.org/10.3319/TAO.2005.16.2.377(Oc).

Wu, H., 2015: Cross-shelf penetrating fronts: A response of buoyant coastal water to ambient pycnocline undulation. J. Geophys. Res. Oceans, 120, 5101-5119, https://doi.org/ 10.1002/2014JC010686.

Xiao, H., X. G. Guo, and R. S. Wu, 2002: Summarization of studies on hydrographic characteristics in Taiwan Strait (in Chinese). J. Oceanogr. Taiwan Strait, 21, 126-138.

Yang, J. Y., 2007: An oceanic current against the wind: How does Taiwan Island steer warm water into the East China Sea? J. Phys. Oceanogr., 37, 2563-2569, https://doi.org/10.1175/ JPO3134.1.

Zhu, D., L. Li, and X. Guo, 2013: Seasonal and interannual variations of surface current in the southern Taiwan Strait to the west of Taiwan shoals. Chin. Sci. Bull., 58, 4171-4178, https:// doi.org/10.1007/s11434-013-5907-y. 